\title{
A Time-Space Diagram as Controller Support Tool for Closed Path Continuous Descent Operations
}

\author{
A.M.P. de Leege ${ }^{1}$, A.C. in 't Veld ${ }^{2}$, M. Mulder ${ }^{3}$, M.M. van Paassen ${ }^{4}$ \\ Delft University of Technology, Delft, The Netherlands
}

\begin{abstract}
Tactical control during a closed-path Continuous Descent Operation stops the aircraft from following its optimized descent. To mitigate tactical control, air traffic controllers apply arbitrary large spacing buffers to account for the unpredictability of the aircraft trajectory from the controller's point of view. A controller support tool is required for early de-confliction, spacing, and sequencing to facilitate these operations without the need to apply large buffers. The Time-Space Diagram controller support tool was developed to make the constraints and complexity of a Continuous Descent Operation perceptually evident and provide tools and information to the controller to be an active problem solver. This paper addresses the further development and validation of the interface. The concept of Visual Momentum was applied to enhance the efficiency of working the multi-display interface that consists of the Plan View Display and Time-Space Diagram. Direct Manipulation Interfaces were added to enable the controller to plan and implement actions, such as speed and altitude control. A controller-in-the-experiment was setup to validate the interface. In the experiment the subjects used either the Time-Space Diagram support tool or a stack list that provided the required spacing and time to lose or gain as a baseline. Both interfaces enabled the subjects to space the aircraft safely and efficiently. Compared to the baseline, the TimeSpace Diagram interface freed time to plan traffic ahead using the Direct Manipulation Interfaces, which according to all subjects worked intuitively. The number of instructions per aircraft was decreased by $25 \%$. Early accurate speed control was applied and use of heading vectors was no longer necessary in most scenarios. As a result aircraft commenced their continuous descent at a higher altitude and greater distance from the runway. The controller workload was significantly reduced and the level of Situational Awareness increased.
\end{abstract}

\section{Introduction}

$\mathrm{C}$ ontinuous Descent Operation (CDO) has been identified by ICAO, SESAR and NextGen to improve the environmental performance of air transport. ${ }^{1-3}$ Aircraft on CDO descend from an optimal position with minimum engine thrust. Benefits include reduced noise, fuel-burn, and emissions when compared to conventional approaches. ${ }^{3}$ In a closed-path CDO procedure the lateral path is fixed. This allows for optimization of the vertical profile by the Flight Management System for the best aircraft performance. However, tactical control when the aircraft is on CDO is likely to stop the aircraft from flying the optimized CDO; hence the economical and environmental benefits are (partially) lost. Key factor in whether tactical control is needed during the CDO is the spacing between aircraft at the start of the CDO that is required to ensure separation throughout the entire decent. ${ }^{4,5}$ The required initial spacing can be determined from aircraft trajectories and procedures. However, from an Air Traffic Controller's (ATCo's) point of view the CDO trajectories are unpredictable. The length of the procedure, the absence of non-transitional periods, and lack of intent information all contribute to this. ${ }^{6}$ To avoid tactical control

1 Aviation Consultant, To70 B.V., P.O. Box 85818, 2508 CM, The Hague, The Netherlands, E-mail: arjen.deleege@to70.nl

2 Research Pilot, Control and Simulation Division, Faculty of Aerospace Engineering, Delft University of Technology, Kluyverweg 1, 2629 HS, Delft, The Netherlands. Member AIAA. E-mail: a.c.intveld@tudelft.nl

3 Professor, Control and Simulation Division, Faculty of Aerospace Engineering, Delft University of Technology, Kluyverweg 1, 2629 HS, Delft, The Netherlands. Senior member AIAA. E-mail: m.mulder@tudelft.nl

4 Associate Professor, Control and Simulation Division, Faculty of Aerospace Engineering, Delft University of Technology, Kluyverweg 1, 2629 HS, Delft, The Netherlands. Member AIAA. E-mail: m.m.vanpaassen@tudelft.nl 
during the CDO ATCOs apply arbitrary large spacing buffers at the cost of capacity. ${ }^{7}$ A controller support tool is needed to reduce and eventually to remove the buffers.

The use of a Time-Space Diagram as an ATCo support tool was first described by de Jong. ${ }^{8}$ The Time-Space Diagram is presented on a second display next to the Plan View Display (PVD) and gives a graphical representation of the current and future traffic situation in the time-space reference frame. Tielrooij et. al. implemented the TSD in a real-time simulation environment for initial validation. ${ }^{9,10}$ It was concluded that the TSD had the potential to be a support tool for CDOs. ATCos reported the TSD prompted a change in the arrival strategy from a first-come firstserve sequence to the sequence predicted by the TSD and a shift from tactical conflict avoidance to strategic metering. The ATCos also raised problems with the presentation of information on the TSD. Secondly, the ATCos indicated difficulties assessing the impact of a certain instruction on the traffic situation. In 2009 van der Eijk et. al. continued the development of the TSD. ${ }^{11}$ The layout of the TSD was reviewed and changed to make the interface more clear and self-explanatory. To support the ATCo in assessing the impact of an instruction a function to add 'hypothetical predictions' showing the effect of a range of possible instructions was developed. Validation of the enhanced interface confirmed the results from the initial validation and indicated a reduction of the controller workload and the number of instructions compared to a baseline in which the controller was not supported. The ATCos' responses on the function to show 'hypothetical predictions' were mixed. Not all ATCos were convinced of the usefulness and the function was not used by all controllers. No significant effects on the performance were found. Also ATCos suggested a better integration of the PVD and TSD. A similar comment was made by ATCos participating in the evaluation of a $4 \mathrm{D}$ trajectory planning tool, which also uses a PVD and TSD. ${ }^{12}$ ATCos repeatedly reported difficulties integrating information displayed on the PVD and TSD in one mental picture and started focusing on the TSD. This situation is undesired, because the TSD does not provide the information to build a complete mental picture.

This paper addresses the further development and validation of the PVD-TSD interface. The concept of Visual Momentum was applied to enhance the efficiency of working the multi-display interface. Direct Manipulation Interfaces (DMIs) were developed to enable the ATCo to plan and implement his actions as a replacement of the hypothetical predictions. DMIs were developed for conventional controller instructions such as speed, altitude, and heading control, but also for more novel techniques such as a Point Merge system or Required Time of Arrival (RTA). A controller-in-the-loop experiment was setup to validate the interface and to perform the first comparative analysis of the TSD with another support tool.

The impact of the TSD on the controller interface is significant. The TSD displays the traffic in a different reference frame and requires a significant amount of screen real estate. An alternative support tool based on a stack list (STL) was developed. The use of an STL would require minimal changes to the existing interface. The stack list (STL) provided the inter-aircraft required spacing and the time to gain or lose to meet the spacing requirement based on the same trajectory information used to generate the TSD. In the experiment six subjects controlled arriving traffic inbound to one or two Initial Approach Fixes (IAFs) using either the PVD-TSD or PVD-STL interface. Subjective ratings of the workload and Situational Awareness (SA) were collected and aircraft trajectories, controller instructions, and the use of the interfaces were logged.

Both interfaces enabled the subjects to accurately space the traffic for CDO. No significant effects on the capacity or safety were identified. The workload was significantly lower when using the PVD-TSD interface at a higher level of Situational Awareness. Fewer instructions per aircraft were required and the instructions were given earlier. This enabled the aircraft to start the CDO from a higher altitude at a greater distance from the runway threshold. More use of the fixed routes was made, potentially reducing the flight distance. The DMIs available in the PVD-TSD interface were used to implement and plan actions well ahead before the aircraft was under control. Overall, the subjects indicated that integration of the information on the PVD and TSD was easy and the DMIs worked intuitively.

This paper has the following sections: Section II presents a general operational concept to facilitate closed-path CDO that was used in this research. Also an analysis of the variability of the required inter-aircraft spacing using real flight-data is presented, urging the need for a support tool. Section III introduces the TSD. Covered are the layout and information that can be derived from the TSD. Section IV covers the changes made to the interface to enhance Visual Momentum. The DMIs are discussed in Section V. The setup of the controller-in-the-loop experiment is discussed in Section VI. Sections VII, VIII, IX contain the results, discussion and conclusions. 


\section{Air Traffic Control for Closed Path Continuous Descent Operation}

\section{A. Continuous Descent Operation}

A CDO is defined as an operation, enabled by airspace design, procedure design and Air Traffic Control ((ATC) facilitation, in which an arriving aircraft descends continuously, to the greatest possible extent, by employing minimum engine thrust, ideally in a low drag configuration. ${ }^{13}$

Two main design options for CDO procedures are open and closed path designs. ${ }^{13}$ Although the TSD is targeted to closed path CDO designs; the open path design is discussed for completeness. In open path designs the lateral path to the runway is not predetermined. The distance to the runway is estimated by the ATCo and communicated to the pilot. Based on the Distance-To-Go (DTG) information the pilot determines the descent rate to establish a continuous descent path. The quality of the DTG information provided and possible changes in the DTG due to vectoring affect the $\mathrm{CDO}$ performance and resulting environmental and economic benefits significantly. ${ }^{14}$ Open path CDOs can be readily implemented, but there is a trend towards closed path designs for better CDO performance and efficiency.

In closed path designs a fixed route defines the lateral path of the aircraft. The exact distance to the runway is known prior to the start of the CDO. This allows for optimization of the vertical profile of the CDO within the constraints set by ATC. The optimized vertical profile is aircraft specific. Main determining factors are aircraft performance, aircraft weight, descent-logic, and weather conditions. ${ }^{4}$ In the remainder of this paper the term CDO refers to a closed path CDO.

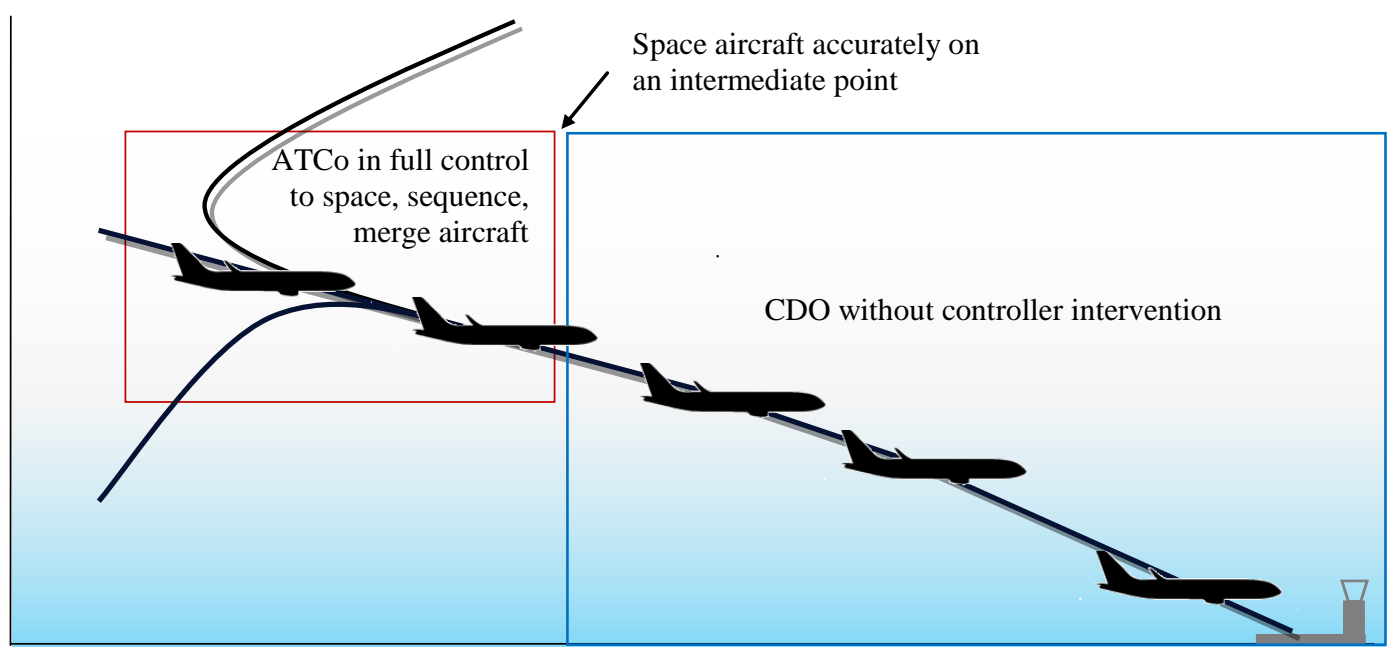

Figure 1. Schematic view of a typical concept of operations for closed path CDO. Aircraft are accurately spaced on an intermediate fix to avoid controller intervention during the CDO

\section{B. Air Traffic Control for CDO}

Figure 1 gives a schematic overview of a typical concept of operations to facilitate CDOs. Aircraft fly a CDO from Top of Descent (TOD) or an intermediate altitude to the runway. It is the task of the ATCo to early de-conflict, sequence, and space the aircraft before the CDO commences. To attain maximum throughput and avoid tactical control, aircraft are spaced on an intermediate metering fix. The spacing between aircraft should allow for an undisturbed CDO past the intermediate fix and efficient handling of traffic. Because of the differences in the speed and altitude profiles between aircraft, the required spacing varies per aircraft pairing. To illustrate the differences between aircraft pairs, Fig. 2 shows the observed distribution of the required spacing for a fix at $63 \mathrm{NM}$. The distribution was created using flight data of aircraft landing at Amsterdam Airport Schiphol in the Netherlands. All aircraft followed the nightly CDO procedure from the same IAF. To rule out possible ATC effects only aircraft that landed without another landing with a 10 minute interval were considered. To limit the influence of wind aircraft pairs were formed of aircraft that landed within 60 minutes of each other. The $95 \%$ interval of the required spacing ranges from $5 \mathrm{NM}$ to $16 \mathrm{NM}$, depending on the aircraft pairing and weather conditions. Hence, the use of a fixed interval that ensures an undisturbed CDO for most aircraft pairings will incur a significant capacity penalty. 
Tailoring of the inter-aircraft spacing based on the expected trajectories is required. The required inter-aircraft spacing is not readily available to the controller. A controller support tool is required that provides the ATCo with the information and tools required to accurately space aircraft for CDO.

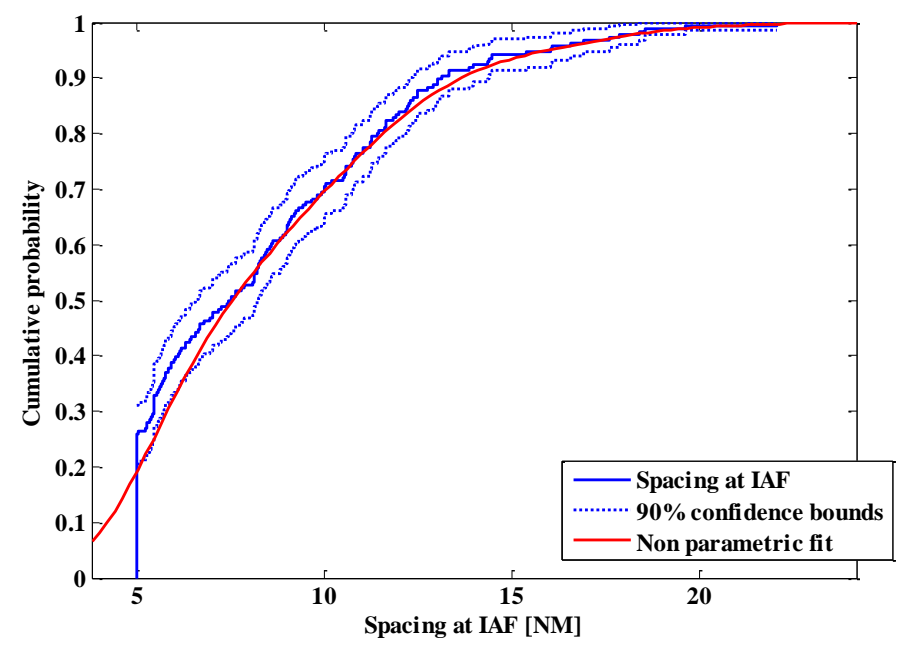

Figure 2. Cumulative probability of required spacing at IAF based on ADS-B data

\section{The Time-Space Diagram as a Controller Support Tool}

\section{Applications of Time-Space Diagrams}

Time-space diagrams are commonly used to solve transportation related problems, for example in traffic and highway engineering. ${ }^{15}$ The time-space diagram is a visual tool for engineers to analyze a coordination strategy and modify timing plans for traffic signals. ${ }^{16}$ An example in airport planning and management is the is the estimation of runway capacity. ${ }^{17}$ In this research the diagram is used to support the controller in sequencing, merging and spacing of aircraft based on aircraft trajectory predictions. In line with the Ecological Interface Design (EID) approach the TSD provides tools and information to the controller to be an active problem solver. ${ }^{18}$

\section{D.Time-Space Diagram Layout}

The TSD gives a graphical representation of the current and future traffic situation in addition to the information provided on the Plan View Display (PVD). Figure 3 gives a schematic view of the TSD for two in-trail aircraft following a fixed arrival route to the runway threshold. The diagram is build up of two axes. The vertical axis is the time-axis. Aircraft labels are shown on the axis at the Estimated Time of Arrival (ETA) at the runway threshold. The time-axis together with the aircraft labels is a typical Arrival Manager interface. The labels from top to bottom show the arrival sequence. The DTG to the runway threshold is drawn on the horizontal axis. Plotted in the diagram are trajectory predictions. Presentation of the aircraft requires that all trajectories have at least one point in common. For arriving traffic on a single runway this conditions is always met by selecting the runway threshold.

The diagram is complemented with task relevant information such as the separation minima and existing conflicts. The separation minima are visualized using shaded areas and referred to as the separation areas. The separation areas are attached to the trajectory of the leading aircraft. Both time-based and distance-based separation minima can be visualized. Areas associated with a distance-based separation minimum (e.g. wake vortex or radar separation) will be constant in the DTG (horizontal) direction, whereas time-based separation minima will result in an area with a constant time-interval. The separation minima are only visualized when the aircraft are in proximity or when the leading aircraft is on final approach. Hence, for two aircraft coming from two different directions the area is only shown when the aircraft are about to merge onto the same route and when in trail. 


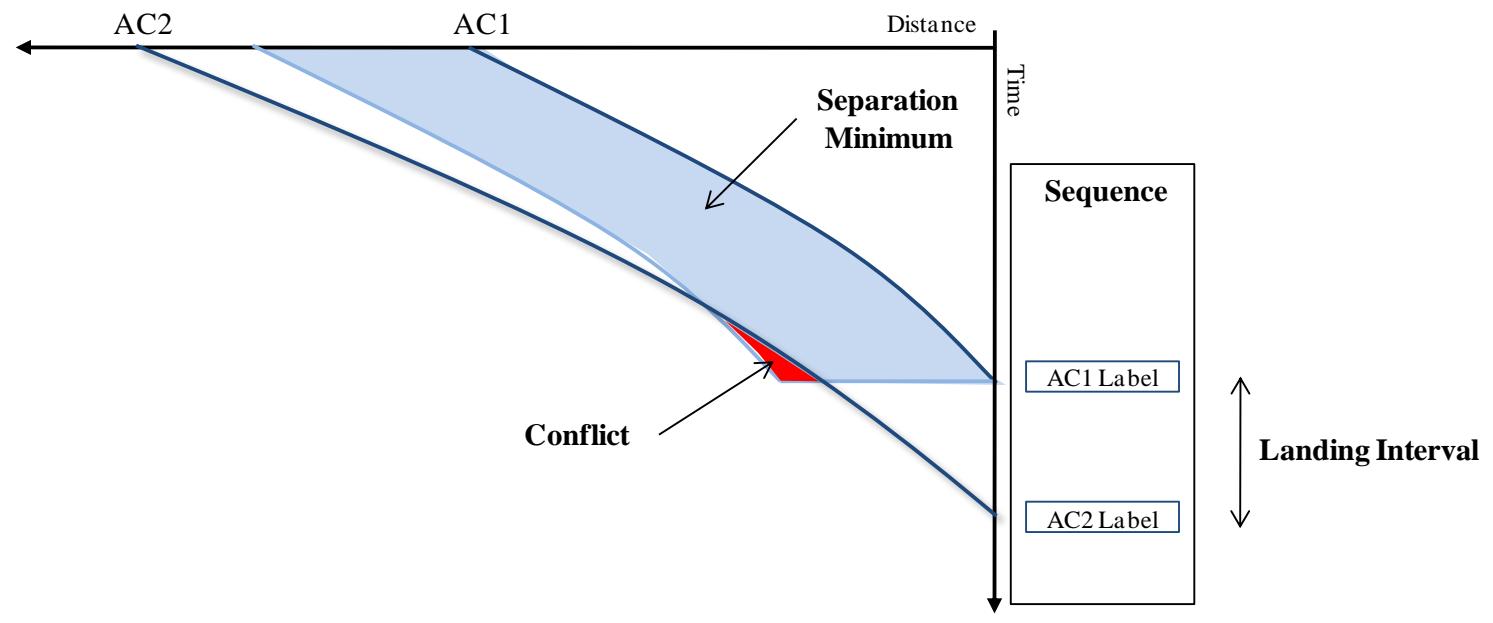

Figure 3. Time-Space Diagram Layout

If a trajectory crosses a separation area and the aircraft are not separated by altitude there is conflict. To visualize a conflict the area enclosed by the trajectory of the trailing aircraft and separation area is colored red. This representation also embodies information about the time in conflict and the expected loss of separation. The location on the TSD shows the time and current distance to resolve the conflict. The task of selection, decision making, and implementation of resolving actions is left to the ATCo. Once an action is implemented (e.g. speed instruction is given) the TSD is updated.

\section{E. Hypothetical Predictions}

To support the ATCo in his task, a function to show 'hypothetical predictions' was developed. ${ }^{11}$ When initiated by the ATCo the TSD generated various possible controller actions and showed the result to the ATCo. Figure 4 gives an example of speed control to resolve a conflict. The two dashed lines represent the predicted trajectories for speed instructions selected by the system. The design of this support function is reviewed in section V. Based on this analysis and the feedback from controllers the use of DMIs is proposed.

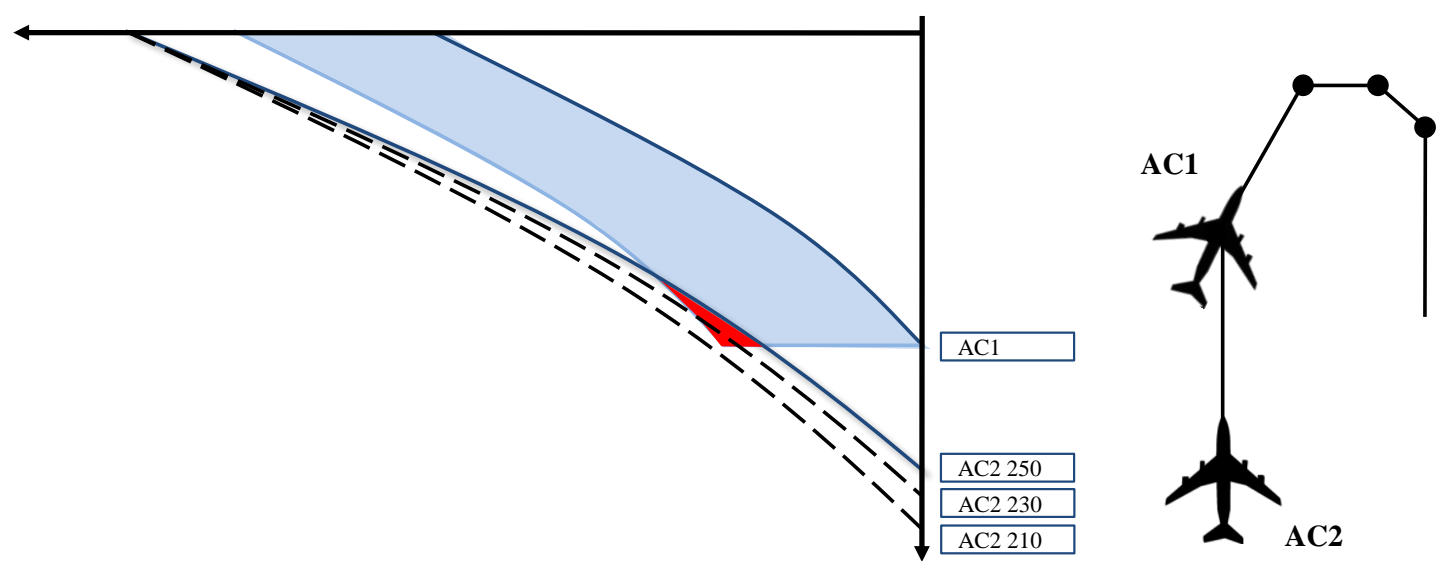

Figure 4. Speed Control support on the TSD

\section{F. Trajectory Prediction}

The PVD-TSD is the interface between the ATCo and a trajectory predictor. In parallel with the development of the PVD-TSD interface, a trajectory predictor was developed. To plot an aircraft trajectory on the TSD, an unambiguous trajectory from the current position to the runway threshold is required. Based on the current aircraft state, weather, ATC clearances, intent, and procedures the predictor generates a flight plan that describes the lateral 
and vertical path of the aircraft. Next, the predictor generates a trajectory by following the lateral and vertical path. The lateral and vertical control and guidance system of the predictor were developed based on the design of Aircraft Dynamics Model for the FAA Target Generation Facility, the workstation based fast-time aircraft simulator for noise abatement approach procedure study described by Ren et. al. ${ }^{19,20}$ For aircraft performance data and computations use is made of EUROCONTROL's Standard Aircraft Modeling Interface (SAMI) and BADA or GAME aircraft performance models. ${ }^{21-23}$ Finally, the predictor was tuned using actual flight data.

\section{Visual Momentum}

The PVD and TSD are presented on separate displays and provide information in a different frame of reference. To improve integration of information from the multi-display PVD-TSD interface, the interface has been evaluated using the Visual Momentum. Subsequently, changes have been made to the interface to increase the amount Visual Momentum.

\section{G. Concept of Visual Momentum}

The concept of Visual Momentum refers to the impact of a transition from one view to another on the ability of the observer to extract task-relevant information. ${ }^{24}$ Woods definition of Visual Momentum is: "The amount of visual momentum supported by a display system is inversely proportional to the mental effort required to place a new display into the context of the total data base and the user's information needs." When visual momentum is high, successive views support the rapid comprehension of data following the transition to a new display. In case the visual momentum is low, reorientation from scratch is needed when moving across displays. A technique to increase the Visual Momentum is the use of 'longshots'. Longshots help the user to step back from the details of the monitored process to assess the overall system status and to decide where to look next. ${ }^{24}$

\section{H. Review of changes to interface design}

In the PVD-TSD interface the TSD provides a longshot. A summary of the traffic situation is given in graphical form. The conflicts and gaps in the arrivals sequence indicate where actions are required. To increase Visual Momentum, the review focused on the three functions contributing to the effectiveness of a longshot: ${ }^{24}$

\section{Status Summary Function}

The status summary function is expected to provide task relevant status information. The summary information must be distilled and abstracted and enable "check reading". The TSD displays the task relevant information as discussed in section III. This information is abstracted from lower level information: the aircraft under control, trajectory predictions, the airspace structure and procedures. The information is presented in a recognizable form using lines, areas and different colors. No changes to the interface were made to improve the status summary function.

\section{Orienting Function}

The orienting function helps the ATCo to orient to where he is relative to the set of available views and to comprehend cuts from one view to another and result in better information integration. For the orienting functions it is required that the longshot is always visible and is coordinated with the other views and includes relevant frames of reference. ${ }^{7}$ The first principle is met since the TSD and PVD are displayed in parallel on two separate screens. Coordination between the TSD and PVD has been added. The changes are depicted in Fig. 5. The coordination is triggered by the selection and deselection of aircraft, conflicts, or separation areas. These actions were interpreted as a decision by the ATCo on the next action to take (e.g. which aircraft to control). The coordination should support the controller where to look next in the interface for the required information. For this purpose both the PVD and TSD were changed. On selection of an aircraft in either display the trajectory is plotted in the PVD, see (1) in Fig. 5. When involved in a conflict, the conflict and the trajectory of the conflicting aircraft are also plotted, see (2) in Fig. 5. On the TSD the color of conflicts the selected aircraft is not involved are darkened. On selection of a conflict area (3), the trajectories of the aircraft involved in the conflict are plotted in the PVD. Similarly, on selection of a separation area (4), the trajectories of the associated aircraft are plotted. Finally, consistent use of colors is made, e.g. for the color of the label indicating the aircraft control status (5)

\section{Movement Function}

The movement function should indicate how the controller can move to an area of interest within the display structure. The display structure consists of the PVD and TSD which are displayed in parallel. There is no navigation 
through the interface using a menu of map. No changes were made to the interface to enhance the movement function.
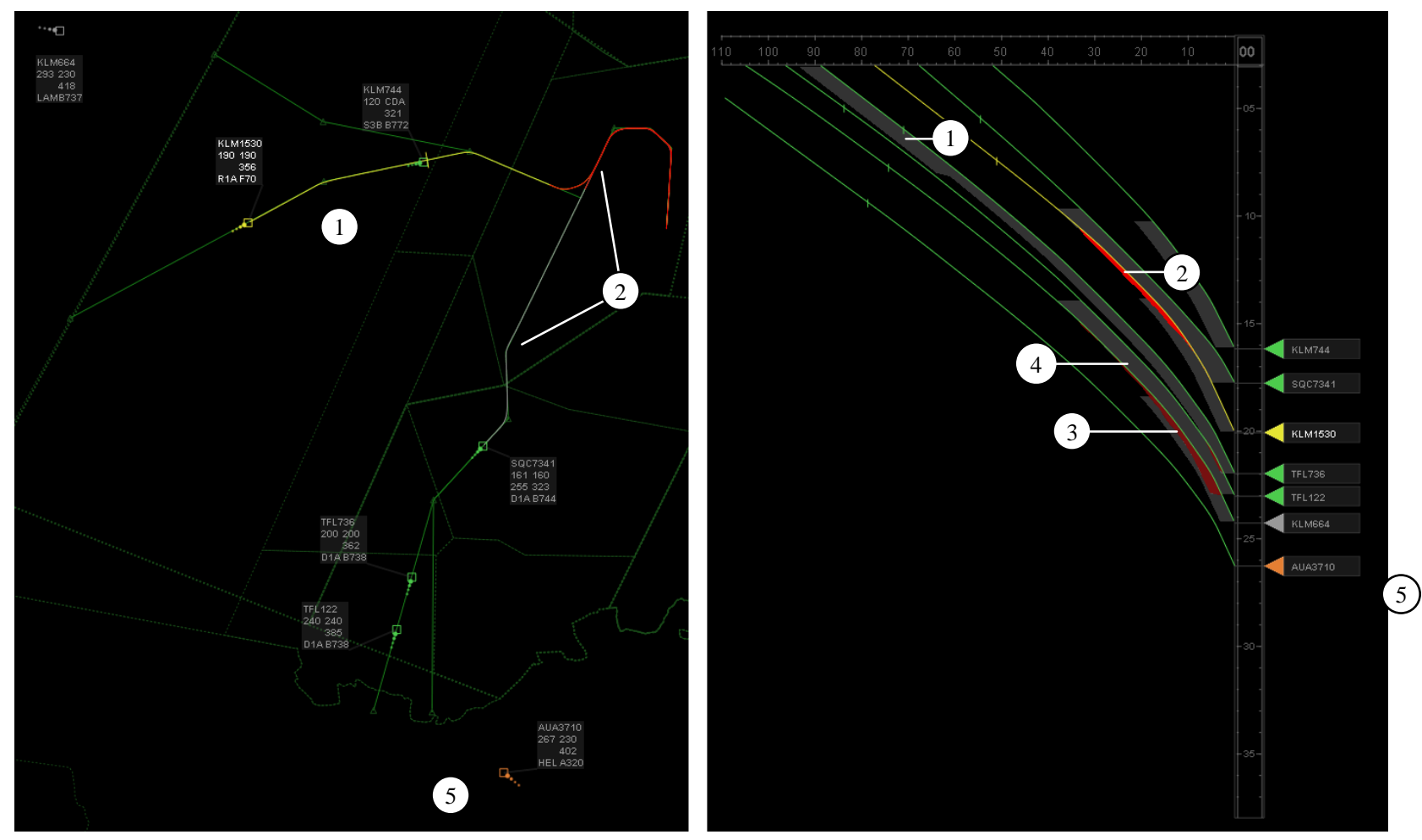

Figure 5. Interface changes to increase Visual Momentum

\section{Direct Manipulation Interfaces}

As outlined in section III the TSD included a function to show the effect of possible actions on the traffic situation. It is proposed to replace these 'hypothetical predictions' tools with DMI. The motivation is threefold. First, the existing interface shows the effect of computer selected actions. Typical short-cuts and speeds were selected based on the aircraft current position and speed. However, no conflict resolution or planning algorithm was involved in the decision process. As a result the actions would not necessarily resolve a conflict or close gaps in the sequence. This limits the usefulness of the tool to providing the ATCo with an order of magnitude an instructions could have. Secondly, the display of various possible actions cluttered the display. Thirdly, the use of DMIs is expected to enhance SA and to reduce performance disadvantages induced by automation. ${ }^{25}$

\section{A. Direct Manipulation Interfaces}

Direct manipulation is a human-computer interaction style with the following properties: ${ }^{26}$ (1) Continuous representation of the object of interest. (2) Physical actions or labeled button presses instead of complex syntax. (3) Rapid incremental reversible operations whose impact on the object of interest is immediately visible.

DMIs are suggested to have the following virtues: (1) Novices can learn basic functionality quickly. (2) Experts can work extremely rapidly to carry out a wide range of tasks, even defining new functions and features. (3) Knowledgeable intermittent users can retain operational concepts. (4) Error messages are rarely needed. (5) Users can see immediately if their actions are furthering their goals, if not, they can simply change the direction of their activity.

\section{B. Direct Manipulation Interfaces for ATC}

For the PVD-TSD interface DMIs have been introduced for the following controller instructions: speed, altitude and heading control, direct-to waypoint instructions, route clearances, the Point Merge concept, and RTAs. The type 
of instruction is selected by the controller. Subsequently, properties of the instruction (e.g. speed in case speed control) can be manipulated in the PVD and/or TSD. The impact of an instruction can be directly perceived in either display and entered into the system. The use of the direct manipulation interface can be stopped at any moment after which the situation is reversed. The following sections discuss the DMIs per controller action, using two aircraft in a conflict.

\section{Speed Control through a Direct Manipulation Interface}

Figure 6 shows the PVD-TSD and direct manipulation interface for speed control. On the TSD the trajectory and label based on current clearances is faded. The speed control constraints are visualized by the blue shaded area, see (1) in Fig. 6. Two labels on the right of the TSD mark the constraints. The labels give the minimum and maximum speed (2). The middle label can be moved up and down by the ATCo within the speed limits by dragging the label in TSD or using the mouse wheel (3). The speed changes in increments of $5 \mathrm{kts}$. When the label is moved the traffic situation is updated on the TSD and PVD and the associated speed is displayed in the labels on the PVD and TSD (4). Once the ATCo has set the speed, the speed has to be confirmed and the interface is updated. The DMIs for altitude control, the Point Merge concept, and RTA use the same control mechanisms and graphical representation and are therefore not discussed in detail.
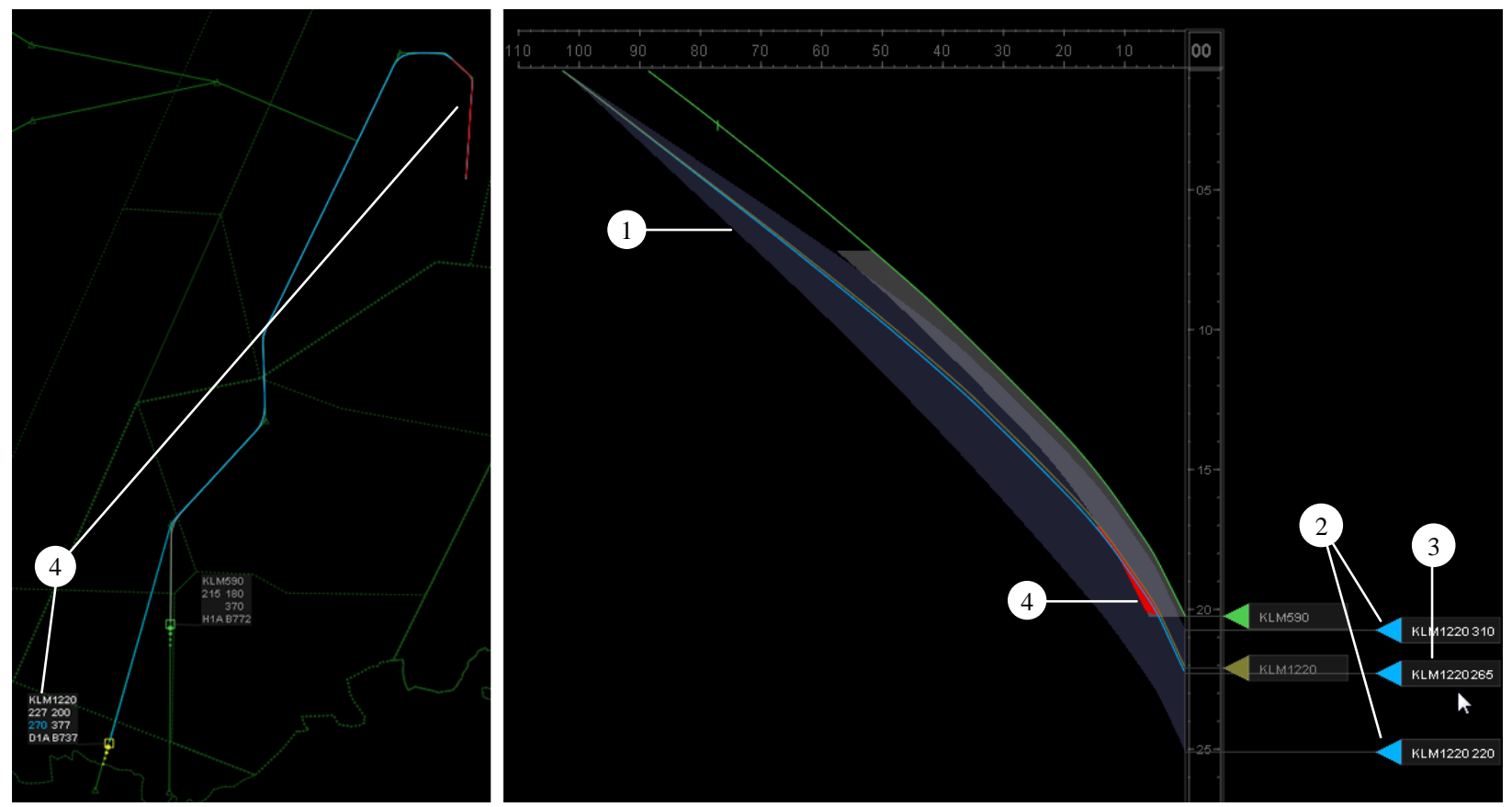

Figure 6. Direct Manipulation interface for speed-control

\section{Direct to Waypoint through Direct Manipulation Interface}

Figure 7 shows the direct manipulation interface for a direct-to waypoint instruction. The ATCo can set the waypoint by clicking in the PVD. The nearest waypoint becomes the waypoint the aircraft will proceed to directly, see (1) in Fig. 7. Alternatively the ATCo can use the mouse wheel to scroll along all the waypoints on the aircraft anticipated route. The selected fixed is also shown in the labels (2). 

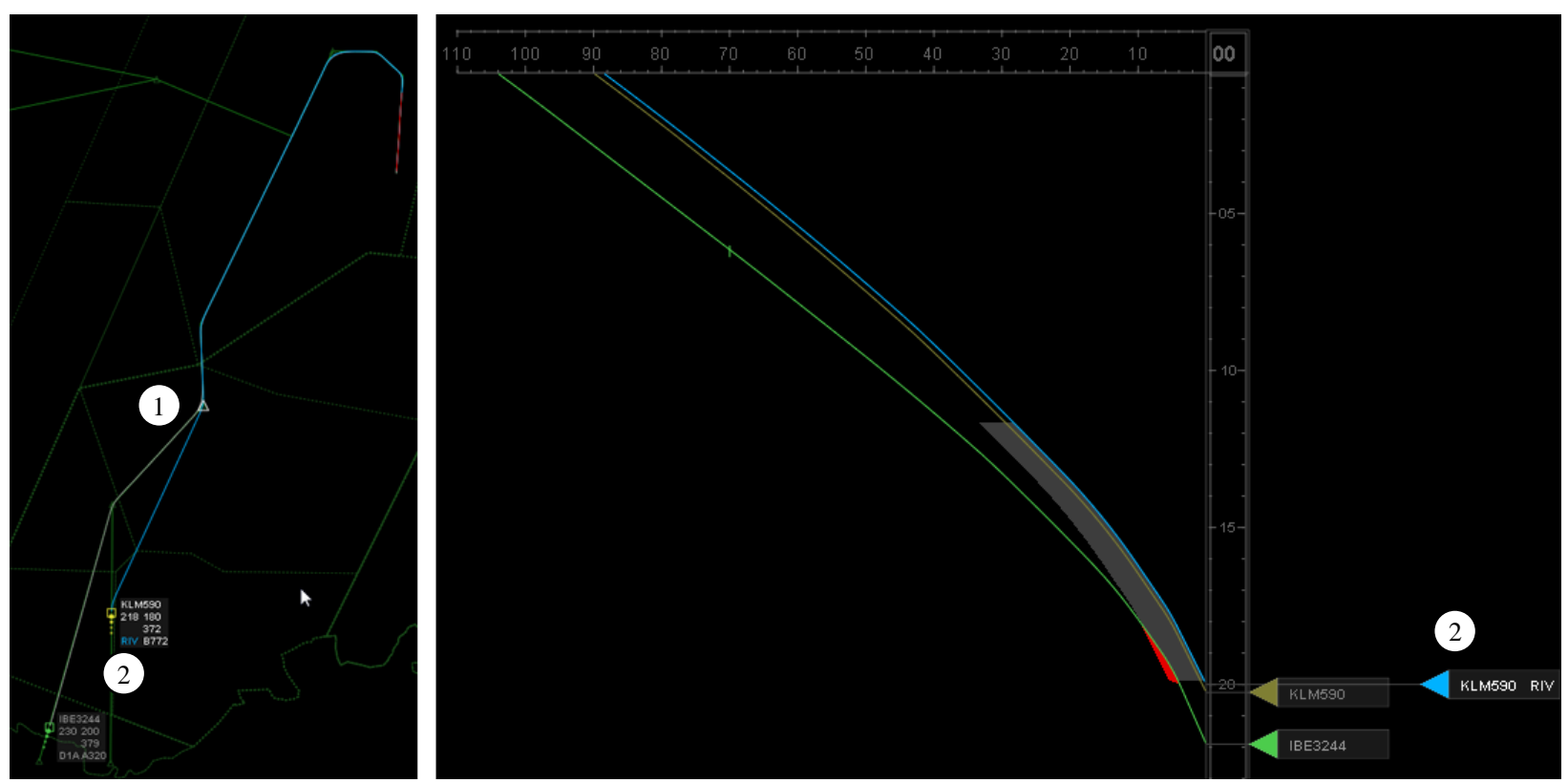

Figure 7. Direct Manipulation interface for direct-to waypoint action

\section{E. Heading Vectors through Direct Manipulation Interface}

Figure 8 shows the DMI for heading vectors. The DMI enables the controller to set the aircraft on a heading and determine the effect the length of the heading segment, see (1) in Fig. 8. The heading and segment length are controlled by dragging the heading vector (2). The point the ATCo is planning to let the aircraft intercept the route is given by the triangle (3). This point is set by clicking a waypoint in the PVD. In the situation depicted in Fig. 8 the trailing aircraft is in conflict with the leading aircraft, as can be seen from the trajectory in yellow that crosses the separation area. The heading vector set on the PVD followed with an instruction to proceed to the selected waypoint will resolve this conflict. Once the heading instruction is given, the TSD shows the traffic situation, assuming the aircraft directly flies towards the fix selected by the ATCo, instead of the trajectory set by the ATCo. This choice was made because heading vectors are an open loop technique. The lateral path is not unambiguously fixed until the second instruction is given. If the instruction to intercept the route is given at a different time than anticipated by the interface, this might lead to unexpected situations. By constantly assuming a direct reintercept of the route, the conflict will gradually become smaller, up to the point where the aircraft has reached the position marked by the mouse cursor (1). At that position the aircraft can be instructed to intercept the route and the conflict has been resolved.

\section{F. Route clearances through Direct Manipulation Interfaces}

The DMI for route clearances allows the user to select the route the aircraft is expected to proceed on. The selected route is highlighted. The first route to be highlighted is selected by the interface based on the aircraft position and clearances the aircraft has yet received. The route can be changed by clicking near a route segment in the PVD.

\section{Experiment}

A controller-in-the-loop experiment was setup to validate the PVD-TSD interface. The experiment was performed using an ATC research simulator. The subjects were tasked to expedite and maintain an orderly flow of traffic in one or two area control sectors and space traffic for a CDO. The validation focussed on the effects of the interface and number of IAFs on controller workload and Situational Awareness (SA), controller instructions, safety, capacity, aircraft trajectories, and the use of the interfaces. 

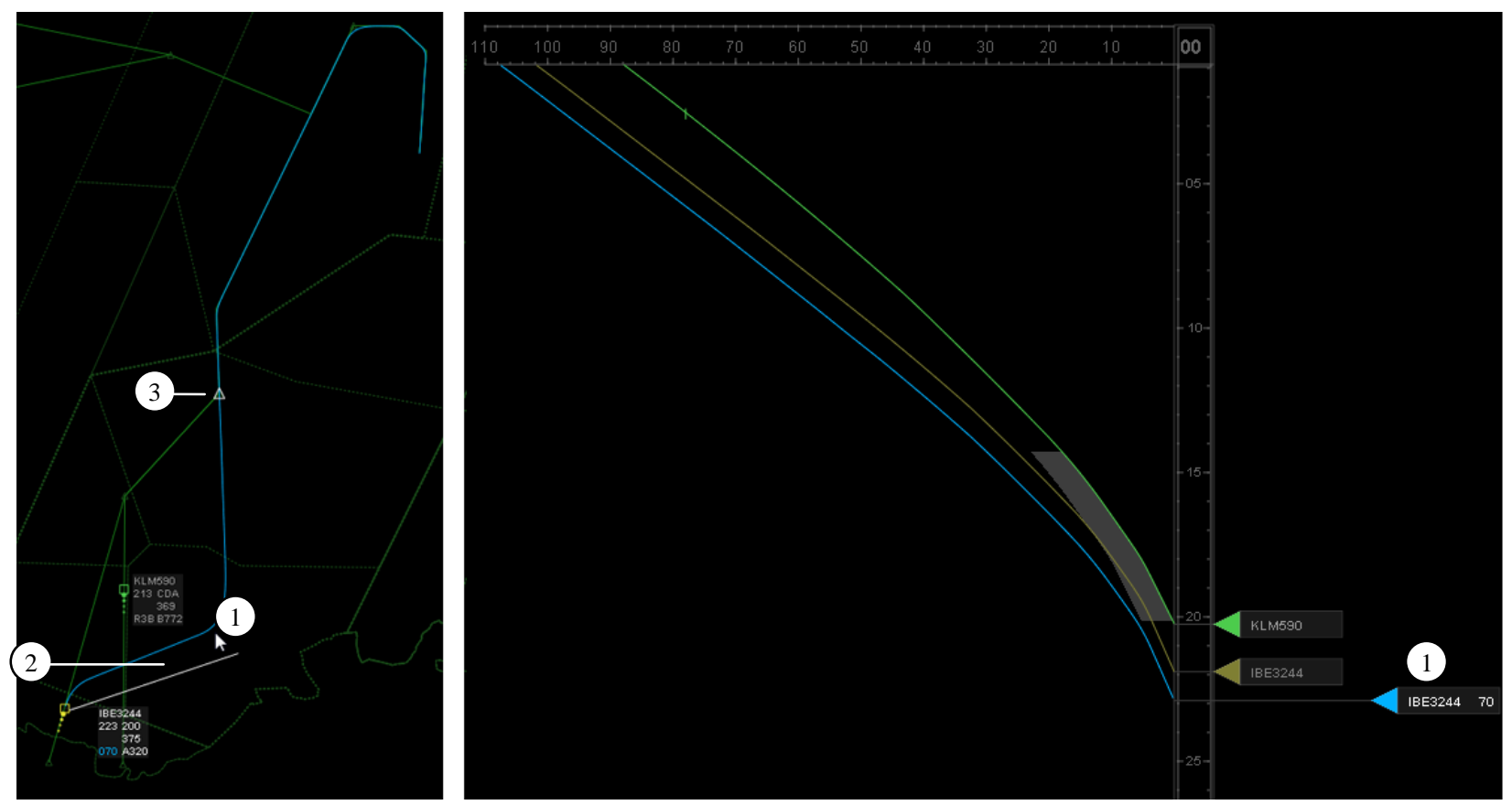

Figure 8. Direct Manipulation Interface for Heading Vectors

\section{A. PVD-STL Interface}

Figure 9 shows the PVD-STL interface with inverted colors. The STL provides the information required to space the aircraft based on the same trajectory predictions used for the TSD. The STL is an inset on the PVD. The leftmost column gives the planned arrival sequence. The top aircraft is planned to arrive first. The order can be changed by the ATCo. The second column gives the IAF of the aircraft. The third column gives the call sign for the leading aircraft that is on the same IAF, if available. The fourth column provides the required spacing with respect to the leading aircraft at the IAF expressed in NM. The fifth column gives the time to lose or gain at the IAF to meet the spacing requirement in steps of 10 seconds. A positive number indicates the aircraft is late and should gain time. A negative number in red indicates that the aircraft arrives too early at IAF resulting in a conflict. The sixth column was added to show the propagation of delay and bunching. The time an aircraft has to lose or gain is added to the total delay except when the aircraft arrives too early and the total delay is positive. In that case the total delay is set to the time the aircraft needs to lose. In the STL in Figure 9 the second, third, and fourth aircraft in the arrival sequence arrive late at the IAF. The actual spacing at the IAF will be larger than the spacing required. The delay accumulates as can be seen in the last column. The fifth aircraft is $90 \mathrm{~s}$ early. The accumulated delay is also set to $90 \mathrm{~s}$. Aircraft number six is $110 \mathrm{~s}$ late with respect to the fifth aircraft. Taking into account the $-90 \mathrm{~s}$ delay of aircraft five, aircraft six is only $20 \mathrm{~s}$ late. The seventh aircraft arrives $-80 \mathrm{~s}$ with respect to the sixth aircraft and again the accumulated delay is set to $-80 \mathrm{~s}$. Aircraft eight and nine arrive $50 \mathrm{~s}$ early and $20 \mathrm{~s}$ late respectively. Taking into account the $80 \mathrm{~s}$ that have to be lost upstream both aircraft have to be delayed. 


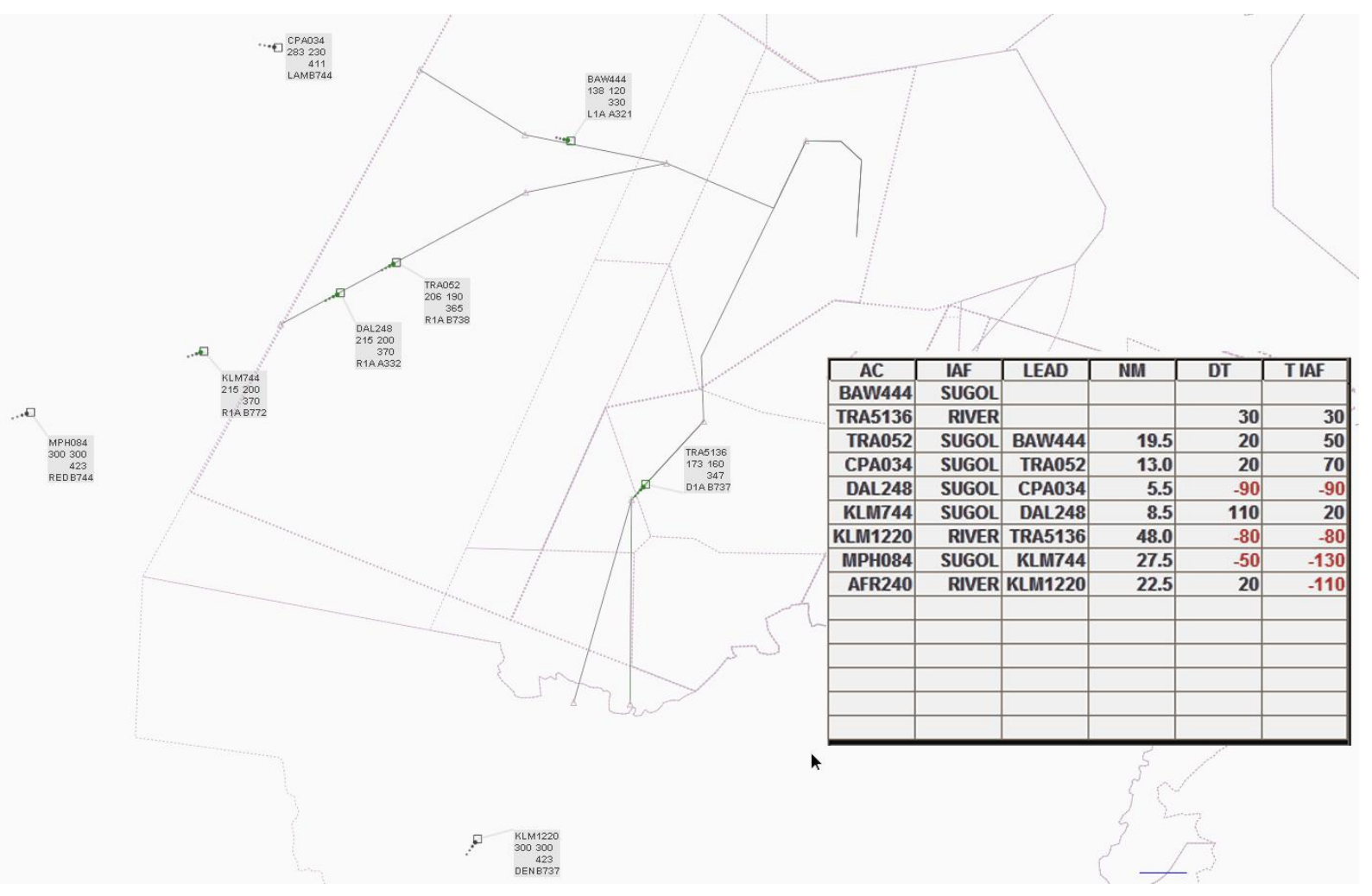

Figure 9. PVD - Stack list interface to support CDO

\section{B. Method}

1. Subjects and Experience

Six subjects were invited to participate in the experiment, see Table 1. The subjects had a background in ATM research and consultancy or worked as an ATCo. The age of the subjects ranged from 26 to 58 years.

Table 1. Overview of Subjects

\begin{tabular}{lcc}
\hline \hline ID & Age & Relevant Experience \\
\hline S1 & 44 & Basic air traffic controller course and subject in many ATC interface experiments \\
S2 & 58 & ATCo Tower/Approach for 25 years \\
S3 & 27 & Interface design for inbound planning and managing 4D trajectories \\
S4 & 26 & Basic air traffic controller course and aviation consultant \\
S5 & 26 & Virtual ATC and subject in various ATC interface experiments \\
S6 & 35 & Basic air traffic controller course and subject in various ATC interface experiments \\
\hline \hline
\end{tabular}

\section{Independent Variables}

The experiment had two within-subject independent variables: The controller interface (INTERFACE) with two levels: PVD-STL and PVD-TSD. The second independent variable IAF had two levels: one IAF and two IAFs. There were four experiment conditions.

Table 2. Overview of Experiment Conditions

\begin{tabular}{lcccc}
\hline & PVD & STL & TSD & IAF's \\
\hline PVD-STL-1 & $\mathrm{X}$ & $\mathrm{X}$ & & 1 \\
PVD-STL-2 & $\mathrm{X}$ & $\mathrm{X}$ & & 2 \\
PVD-TSD-1 & $\mathrm{X}$ & & $\mathrm{X}$ & 1 \\
PVD-TSD-2 & $\mathrm{X}$ & & $\mathrm{X}$ & 2 \\
\hline \hline
\end{tabular}




\section{Airspace and Routes and Procedures}

The airspace and route design were based on the Dutch airspace and Standard Arrival Routes (STARs) and PRNAV transitions leading to a runway at Amsterdam Airport Schiphol. Figure 10 shows the airspace with two area sectors in the West and South and the TMA. Traffic entered the sector at four entry points. At the entry point a STAR started that ended at the IAF (SUGOL, RIVER). At the IAFs transitions to the runway threshold started. The minimum and maximum altitudes over the IAFs were set to FL100 and FL180 respectively. Table 3 gives an overview of the along tracks distances between relevant points.

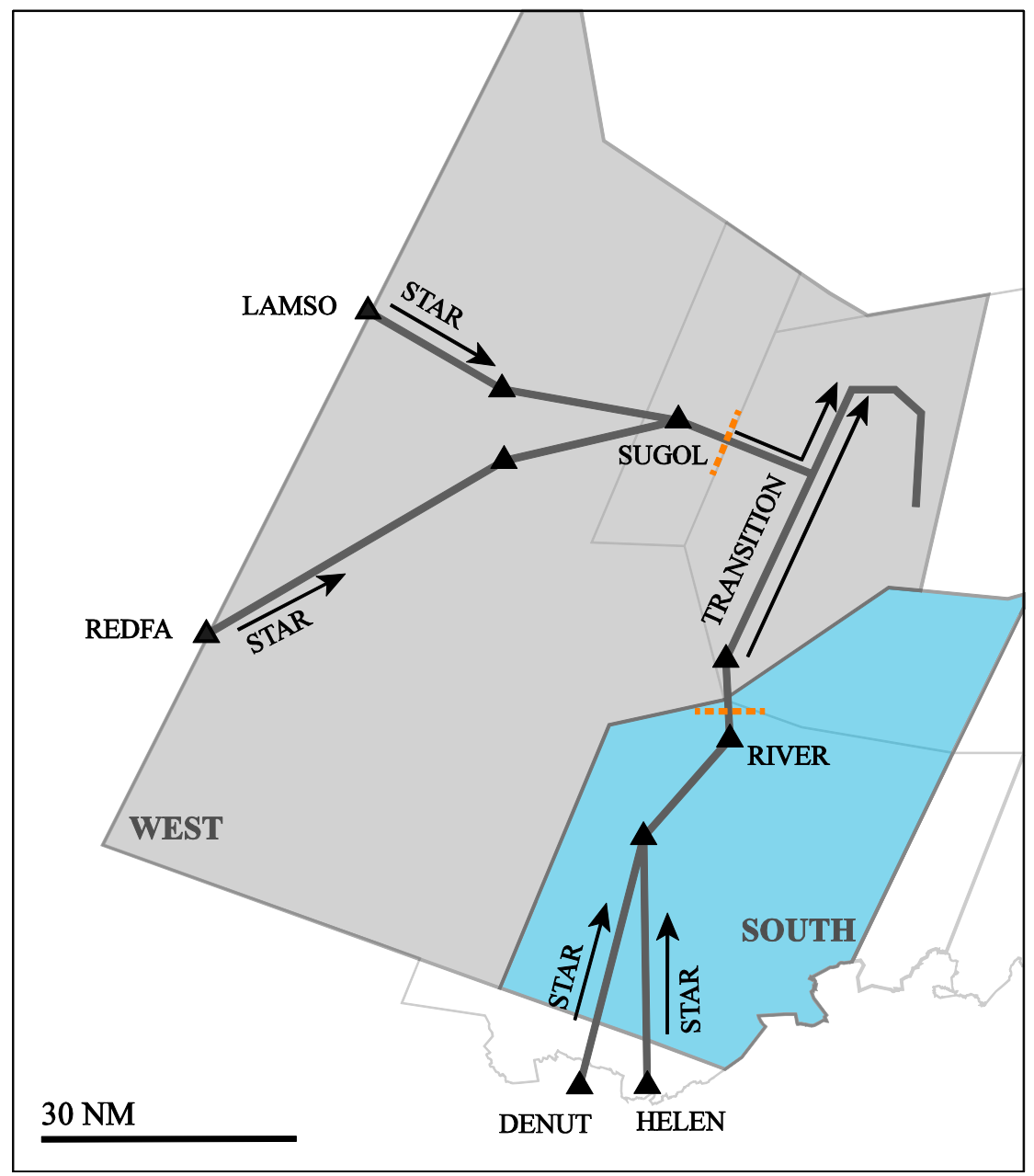

Figure 10. Experiment airspace based on the Dutch airspace

Table 3. Along Track Distances Between relevant points

\begin{tabular}{lcccc}
\hline \hline & RIVER & LAMSO & REDFA & RUNWAY \\
\hline SUGOL & - & 38 & 60 & 48 \\
HELEN & 45 & - & - & 109 \\
DENUT & 46 & - & - & 110 \\
RUNWAY & 64 & 86 & 108 & 0 \\
\hline \hline
\end{tabular}

\section{Traffic Samples}

Four traffic samples were created, each containing 14 aircraft. The traffic was evenly distributed over the entry points. Initially all aircraft were positioned at DTG between $72 \mathrm{NM}$ and $218 \mathrm{NM}$. The inter-aircraft spacing was varied between $7 \mathrm{NM}$ and $16 \mathrm{NM}$ using a sine function to create bunching. To each starting distance an aircraft type and weight were assigned. Aircraft of the types Airbus A320 (4), Airbus A330 (1), Boeing 777 (1), Boeing 747 (2), 
Boeing 737 (5) and Fokker 70 (1) were used. The call signs varied with the entry point. The approximated hourly throughput was $35 \mathrm{AC} / \mathrm{h}$.

\section{Instructions}

The subject was instructed to expedite and maintain an orderly flow of traffic and to space the aircraft for a CDO. On the initial call of the aircraft, the aircraft had to be taken under control. The aircraft were initially cleared direct to the entry point and descending to FL230 or FL240 depending on the entry point. For aircraft under control that were still in the adjacent sector, the subject was instructed not to issue instructions that would change the lateral path. Once in the own sector the subject was free to control both the lateral and vertical paths of the aircraft and apply speed control. The subjects were advised to keep $250 \mathrm{kts}$ as a minimum speed. Within the own sector $5 \mathrm{NM}$ lateral or $1,000 \mathrm{ft}$ vertical separation had to be maintained. Also, the subject was instructed to clear the aircraft for $\mathrm{CDO}$ as soon as possible. Once cleared for the CDO no further instructions could be given.

\section{Apparatus}

The ATC simulator ran on a single workstation. Two identical 20" LCD monitors (1,600 x 1,200 resolution) were used to visualize the PVD and TSD. The subject was positioned in front of the left monitor showing the PVD. The right monitor showing the TSD screen was positioned adjacent to the left screen at a small angle. Input devices were a standard keyboard and a two-button mouse with a mouse wheel. Text-to-speech software was used to provide audio feedback for aircraft calls and read backs.

\section{Dependent measures}

The following dependent measures were used for validation:

\section{Workload}

Two measures were used to assess the ATCo's workload. During the simulation there was an Instantaneous SelfAssessment (ISA) that had to be completed. The subject was asked to indicate the experienced workload every $60 \mathrm{~s}$ using a color bar shown on the PVD and TSD. After each simulation run the subjects completed the NASA Task Load Index (TLX) questionnaire. ${ }^{28}$

\section{Situational Awareness}

After each run subjects completed the EUROCONTROL Situational Awareness for Solutions for Human Automation Partnerships in European ATM (SASHA) questionnaires. ${ }^{29}$ The SHAPE questionnaires serves to obtain a first insight into the impact of a new system on the ATCo's level of Situational Awareness. The questionnaire comprises of six statements that had to be rated on a scale from 0 to 6 . The SASHA Score is the average rating of the statements. Results are to be interpreted in a relative way, in terms of differences in the scores obtained for the four experiment conditions.

\section{Controller Instructions}

All aircraft instructions were logged to determine the number of instructions per aircraft, the type of instructions issued and the timing.

\section{Aircraft trajectories}

The aircraft tracks were logged to analyze the effect of the display configurations both in the vertical and lateral plane. The track miles and vertical profiles were compared between the INTERFACE and IAF conditions.

\section{Safety}

Safety was measured by counting the number of losses of separation when traffic was under control and the number of unresolved conflicts during the CDO phase.

Capacity

The runway throughput was compared between the INTERFACE and IAF conditions.

\section{Use of the Interface}

Controller inputs on the PVD and TSD were logged, including selection of aircraft, conflicts and separation areas, and the use of direct manipulation interfaces. 


\section{Final Questionnaire}

At the end of the experiment there was a final questionnaire. Subjects were asked to rate to which extent they agreed with a statement on a 5-level Likert scale: "strongly disagree", "disagree", "neither agree nor disagree", "agree", "strongly agree". Four statements focused on the availability, integration, and complementarity of information. Seven statements were specific to the PVD-TSD interface. These statements focused on the use of the interface for planning and implementing actions and intuitiveness of the DMIs. Ten statements asked the subjects to rate the level of the difficulty to identify conflicts, solutions to conflicts, gaps in the sequence, knock-on effects, and control of aircraft for both interfaces separately. Again the Likert scale had 5 ratings: "very difficult", "difficult", "neither easy nor difficult", "easy", and "very easy".

Also, the subjects were asked about their control strategy for the two interfaces and suggestions to improve either interface. Finally, the subjects were given the opportunity to provide any comments on the simulator and the experiment.

\section{Experiment Design}

The experiment started with the briefing of the subject and demonstration of the interfaces. To train the subject in using the simulator and the interfaces a series of short videos were used. Also two practice runs were done in the simulator with a focus on controlling the aircraft and simulator. Four training runs followed, in which each experiment condition was trained once. The experiment itself also consisted of four runs per subject. To eliminate practice and boredom effects a Latin square design was used to control variation, see Table 4. Also, the traffic samples were swapped between conditions.

Table 4. Order of experiment conditions following a Latin square design

\begin{tabular}{ccccc}
\hline \hline Subject & \multicolumn{4}{c}{ Order of experiment Conditions } \\
\hline 1 & PVD-STL-1 & PVD-STL-2 & PVD-TSD-1 & PVD-TSD-2 \\
2 & PVD-TSD-1 & PVD-TSD-2 & PVD-STL-1 & PVD-STL-2 \\
3 & PVD-STL-2 & PVD-TSD-2 & PVD-TSD-1 & PVD-STL-1 \\
4 & PVD-STL-1 & PVD-TSD-1 & PVD-TSD-2 & PVD-STL-2 \\
5 & PVD-STL-2 & PVD-STL-1 & PVD-TSD-2 & PVD-TSD-1 \\
6 & PVD-TSD-2 & PVD-TSD-1 & PVD-STL-2 & PVD-STL-1 \\
\hline \hline
\end{tabular}

\section{Procedure}

Each training and measured run started with the simulation in pause. The subject was given the time to familiarize with the traffic situation, adjust the display settings, and arrange the aircraft labels. After the last instruction to simulation advanced at high speed until all aircraft had landed. A NASA TLX and SASHA sheet had to be completed after each run. Directly after completion of the last run the subject had to complete the final questionnaire. Typically the experiment was completed in five hours excluding breaks.

\section{Hypothesis}

Four high-level hypotheses were formulated:

H1. Subjects are able to handle traffic safely and efficiently in terms of throughput with both interfaces;

H2. Use of the PVD-TSD interface results in a reduction of the workload at a higher level of SA;

H3. The number of IAFs has a smaller effect on the performance when using the PVD-TSD interface;

H4. The CDO performance is better when using the PVD-TSD interface. 


\section{Results}

\section{A. Workload}

A box plot of the ISA scores after transformation in z-scores is given in the right panel of Figure 11. The effects of the INTERFACE and IAF on the ISA Score were analyzed using a generalized estimating equations approach. ${ }^{30}$ A linear scale response of the model of the form:

$$
S=\sum \beta_{i} X_{i}
$$

was created. Where:

- $\quad \mathrm{S}$ is the response, in this case the ISA score

- $\beta_{i}$ are the estimates of the effects

- $X_{i}$ are the values of the independent variables and are either 0 or 1 .

The response of the model was the ISA score. Model predictors were the INTERFACE and IAF. Also the subject (SUBJ) was taken into account. Table 5 shows the parameter estimates and hypothesis tests. None of the interactions were significant, and were therefore removed from the table.

Table 5. Parameter estimates and hypothesis tests ISA score model

\begin{tabular}{|c|c|c|c|c|c|c|c|}
\hline \multirow{2}{*}{ Parameter } & \multirow{2}{*}{$\beta$} & \multirow{2}{*}{ Std. Error } & \multicolumn{2}{|c|}{ 95\% Wald Confidence Interval } & \multicolumn{3}{|c|}{ Hypothesis Test } \\
\hline & & & Lower & Upper & Wald $\chi^{2}$ & df & Sig. \\
\hline$[\mathrm{IAF}=1]$ & -.054 & .0133 & -.080 & -.028 & 16.236 & 1 & $<0.001$ \\
\hline$[\mathrm{IAF}=2]$ & $0^{\mathrm{a}}$ & & & & & . & \\
\hline [INT=PVD-STL] & .109 & .0133 & .083 & .136 & 67.652 & 1 & $<0.001$ \\
\hline [INT=PVD-TSD] & $0^{\mathrm{a}}$ & & & & & & \\
\hline$[$ SUBJECT $=1]$ & .023 & .0226 & -.022 & .067 & .993 & 1 & .319 \\
\hline$[$ SUBJECT $=2]$ & -.135 & .0220 & -.178 & -.091 & 37.436 & 1 & $<0.001$ \\
\hline$[$ SUBJECT $=3]$ & -.113 & .0228 & -.158 & -.068 & 24.631 & 1 & $<0.001$ \\
\hline$[$ SUBJECT $=4]$ & -.184 & .0229 & -.229 & -.139 & 64.292 & 1 & $<0.001$ \\
\hline$[$ SUBJECT $=5]$ & -.168 & .0232 & -.214 & -.122 & 52.221 & 1 & $<0.001$ \\
\hline$[$ SUBJECT $=6]$ & $0^{\mathrm{a}}$ & & & & & & \\
\hline
\end{tabular}

a. Set to zero because this parameter is redundant

From Table 5 it was concluded that the INTERFACE and IAF have a significant effect on the workload. The ISA Score for the PVD-STL interface is higher $(+0.109)$ than for the PVD-TSD interface. The ISA score for one IAF is lower than the score for two IAFs (-0.054). The effect of the INTERFACE on the ISA Score was twice the size of the effect the IAF. It was also concluded that subject one and six rated their workload on the ISA scale significantly higher than the other subjects.

The model explained 39\% of variance of all recorded ISA Scores, $r_{s}=0.59, p<0.001$. It should be noted that the model predicted only one ISA Score per subject, INTERFACE, and IAF combination $(\mathrm{N}=24)$. Data analysis showed a variation of the workload during each run, which is not captured by the model. To further verify the validity of the model the scores per run were consolidated into a single score, in this case the median. The variance explained by the model of the consolidated scores was $56 \%, r_{s}=0.754, \mathrm{p}<0.001$.

\section{NASA TLX}

The left panel Figure 11 gives the box plot of the NASA-TLX scores after the transformation into z-scores. A repeated measure ANOVA of the NASA-TLX scores with a Bonferroni correction for the critical level of significance, indicated a significant main effect of the INTERFACE on the NASA TLX score, $F(1,5)=154, p<$ 0.01 . The contrast indicated a very strong effect, $r=0.98$. The medians of the NASA-TLX scores for the PVD-STL and PVD-TSD interface were 33.5 and 14.0, respectively. To assess the sources of the change in workload, the six subscale scores were analyzed. A repeated measure ANOVA of the six subscales showed a significant decrease of 
the effort required to complete the task, $F(1,5)=22.07, r=0.90, p<0.01$. Also the mental demand decreased significantly, $F(1,5)=61.45, r=0.96, p<0.01$. The performance, physical demand, and frustration subscales did not change significantly. The main effect IAF did not significantly affect the NASA TLX score, $F(1,5)=1.46, p=$ 0.28 . Also the interaction between the INTERFACE and IAF did not have a significant effect, $F(2,5)=0.26, p=$ 0.63 .
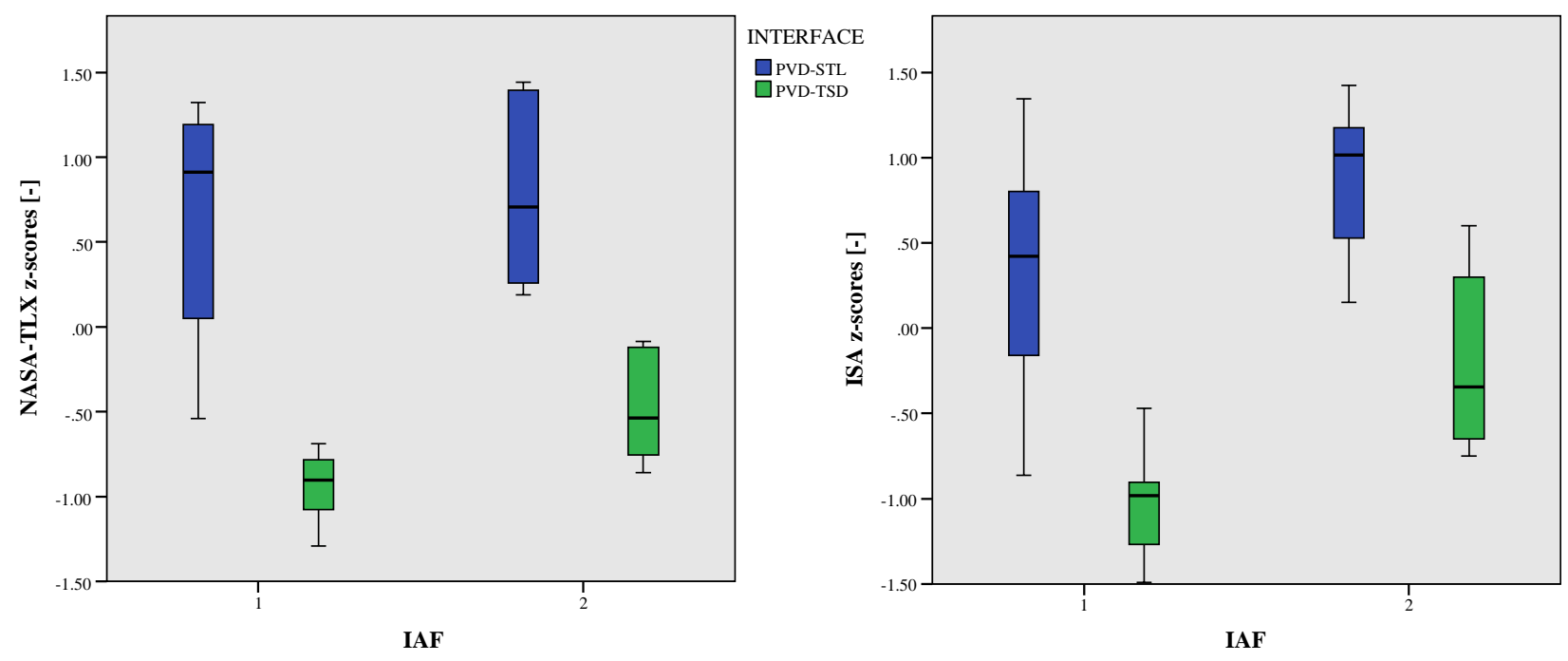

Figure 11. NASA TLX and ISA workload z-scores

\section{B. Situational Awareness}

Figure 12 shows the estimated marginal means of the SASHA scores. The mean SASHA scores for the PVDTSD are higher than the mean scores for the PVD-STL interface.The level of SA reduces when adding a second IAF. Also the impact of the second IAF seems to be larger for the PVD-STL than the PVD-TSD interface. The Kolmogorov-Smirnov test indicated the data for the four experiment conditions were not significantly different from a normal distribution $(p>0.05)$. A repeated measure ANOVA of the SASHA scores, after transformation into zscores, indeed indicated a significant main effect of the INTERFACE on the SASHA score, $F(1,5)=21.41, p<$ 0.01 . Also the main effect IAF was significant $F(1,5)=6.69, p<0.05$. The interaction between INTERFACE and IAF did not have a significant effect.

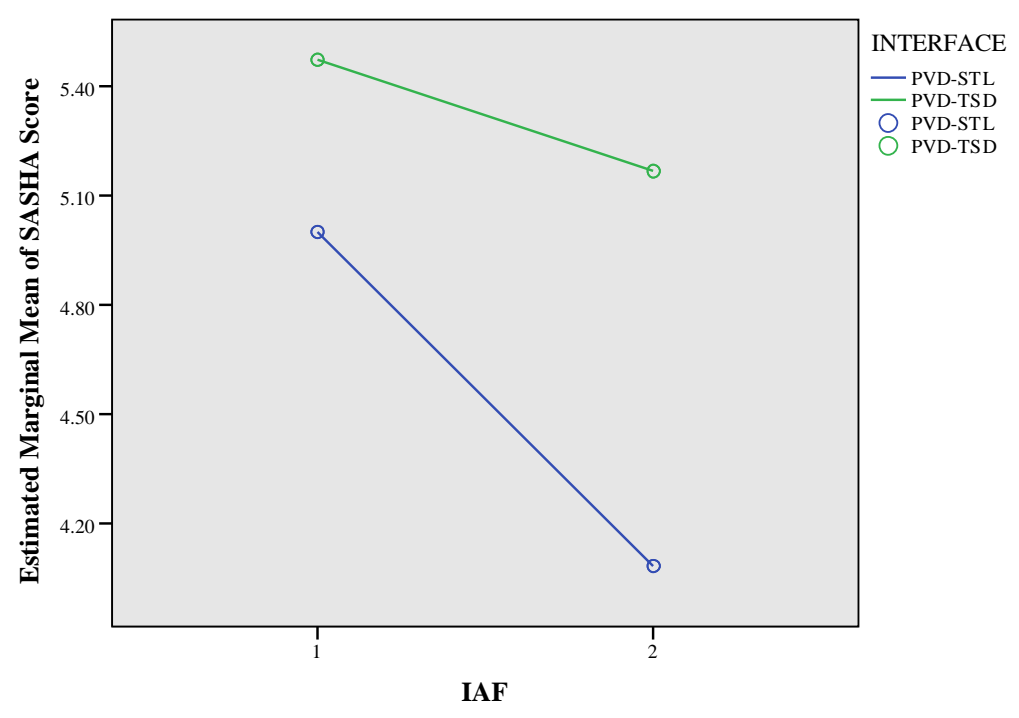

Figure 12. Estimated Marginal means of SASHA Scores 


\section{Interface Use}

\section{Aircraft selections}

Aircraft could be selected on the PVD or TSD when available. The two panels on the left in Figure 13 show box plots for the total number of aircraft selections per INTERFACE. The two panels on the right give the box plots for the number of selections per display (PVD/TSD). A Friedman's ANOVA showed that the total number of instructions changed significantly between the four experiment conditions, $\chi^{2}(3)=11.8, p<0.01$. Wilcoxon signed rank tests indicated that the number of aircraft selections only increased significantly for the PVD-TSD when increasing the number of IAFs from one to two, $z=-2.20, p<0.05$. For those subjects that used the TSD to select aircraft, the number of aircraft selections on the TSD did not increase significantly between IAFs.
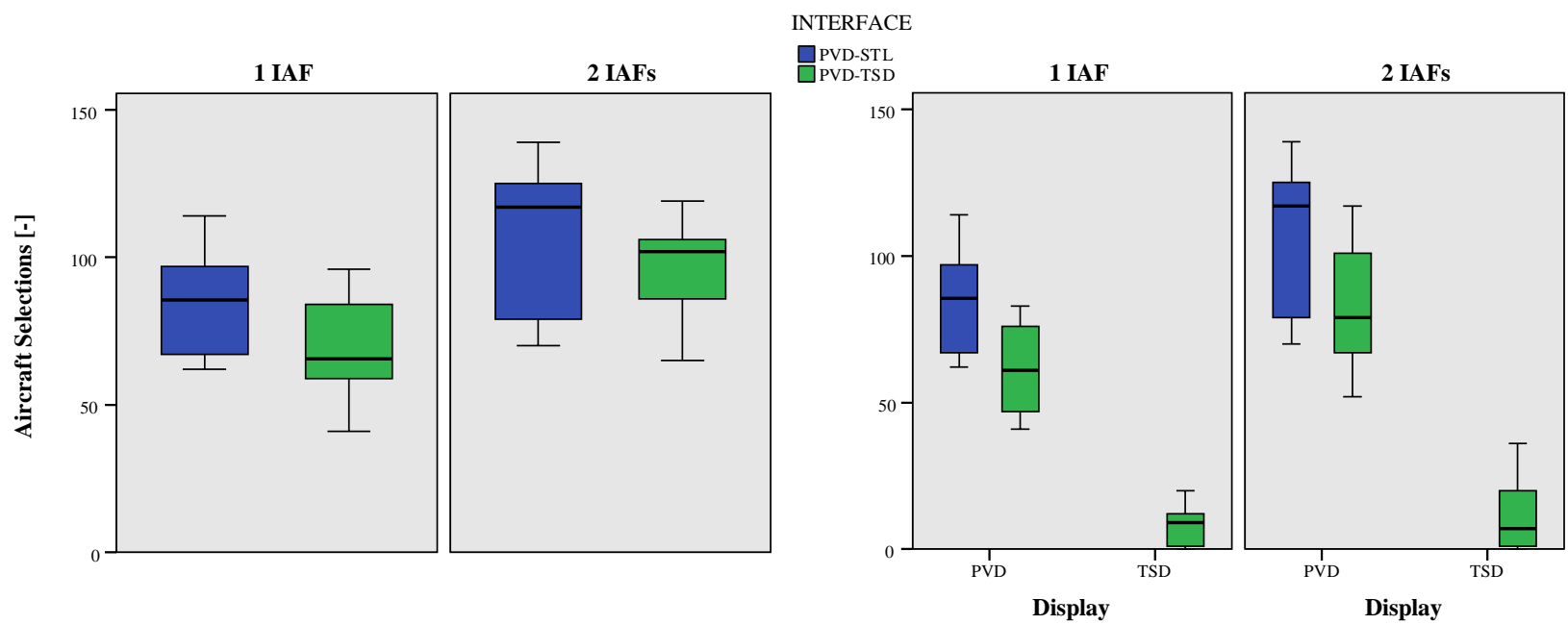

Figure 13. Number of Aircraft Selections per Interface and Display

\section{Use of Support Functions}

Depicted in Figure 14 is the usage of the DMIs. Most used DMIs are for speed control and route clearances. The use of the DMI for speed control increased significantly with the number of IAFs, $t(5), p<0.05, r=0.77$. Use of the other DMIs was not significantly affected by the number IAFs. The DMI for speed control was always controlled using the mouse wheel. Subjects did not use the possibility to drag the label in the TSD to set the speed.

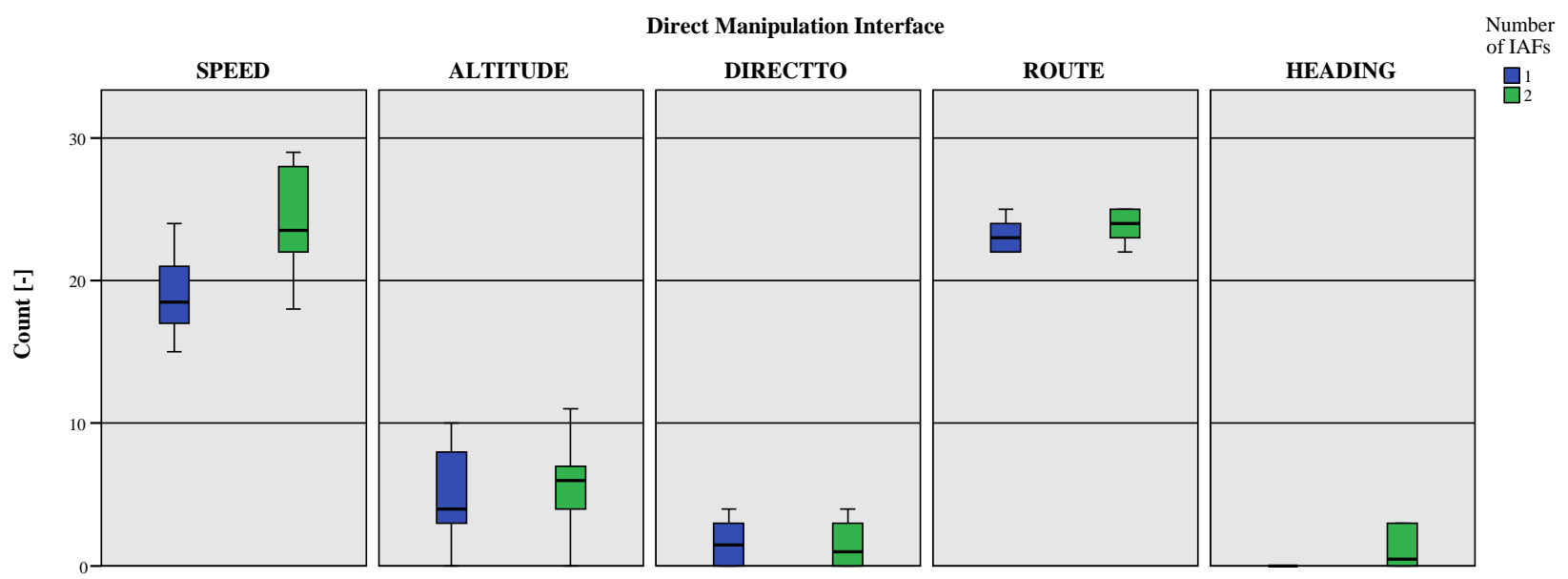

Figure 14. Use of Direct Manipulation Interfaces 


\section{Selections in the TSD}

The subject could select aircraft labels, conflicts, and separation areas in the TSD. From the analysis of the aircraft selections it was already concluded that subjects selected aircraft in the TSD. Selection of the conflict and separation areas was not used by the subjects. Only one subject selected a separation area once.

\section{Number of Controller Instructions}

Figure 15 shows the box plots of the controller instructions per experiment condition. A Friedman's ANOVA showed that the total number of instructions changed significantly between the four experiment conditions, $\chi^{2}(3)=$ $16.93, p<0.01$. Wilcoxon signed rank tests were used to follow up these findings. Controlling the traffic using the PVD-TSD interface instead of the PVD-STL interface for one IAF resulted in a $24 \%$ decrease of the number of instructions, $T=0, r=-0.64, p<0.05$. When controlling traffic for two IAFs there was a significant reduction of $27 \%, T=0, r=-0.64, p<0.05$. The number instructions significantly increased $11 \%$ when adding the second IAF to the scenario and controlling the traffic using the PVD-STL interface, $T=21, r=0.64, p<0.05$. No significant effects were found when controlling traffic using PVD-TSD interface. To further analyze the effects of the INTERFACE and IAFs on the instructions, the analysis was repeated for speed instructions, heading instructions, route clearances, direct to way point instructions, and altitude clearances. The number of speed instructions changed significantly between the experiment conditions $\chi^{2}(3)=13.80, p<0.01$. The number of speed instructions was reduced by $50 \%$ when using the PVD-TSD interface for one IAF, $T=0, r=-0.64, p<0.05$. The reduction as a result of the INTERFACE was the same for two IAFs, $T=0, r=-0.64$. Also the number of heading instructions changed significantly between the experiment conditions $\chi^{2}(3)=13.53, p<0.01$. Heading instructions were no longer used when controlling traffic for one IAF using the PVD-TSD interface. When controlling traffic for two IAFs the number of heading instructions decreased by $75 \%$ when using the PVD-TSD interface compared to the PVD-STL interface, $T=0, r=-0.64, p<0.05$. The number of heading instructions significantly increased with the number of IAFs when controlling the traffic using the PVD-STL interface, T $=15, r=0.64, p<0.05$. No significant effects were found when controlling traffic using PVD-TSD interface. The number of direct-to instructions changed significantly between the experiment conditions $\chi^{2}(3)=11.15, p<0.05$. However no further significant effects within the INTERFACE and IAF were found. The number of route and altitude clearances did not change significantly between the experiment conditions.

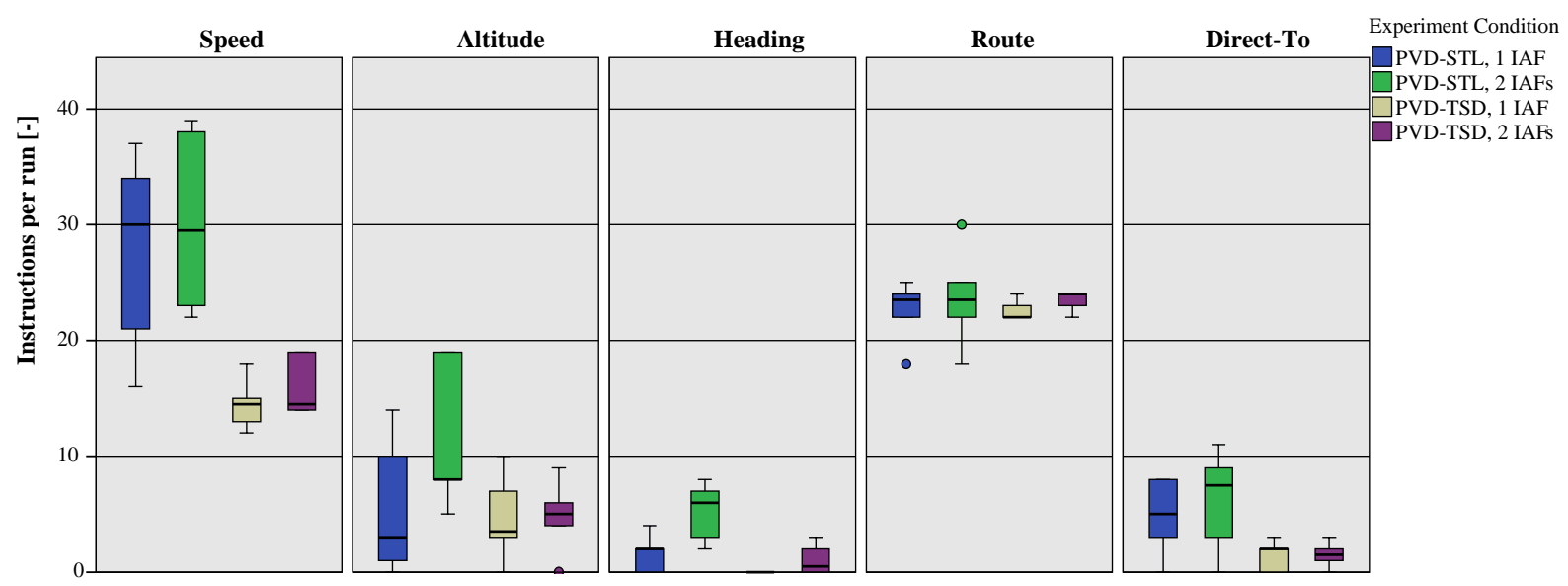

Figure 15. Controller Instructions per Simulation run and Experiment Condition (14 AC)

\section{E. Timing of Controller Instructions}

The timing of the controller's instructions was analyzed by comparing the time between the aircraft initial call and the first and last instructions that were given. The box plot of the time intervals is given in Figure 16. A Friedman's ANOVA indicated a significant effect of the experiment conditions on the time between the initial call and first instruction, $\chi^{2}(3)=10.83, p<0.05$. The left two panels in Figure 16 give the box plots. Wilcoxon test showed a significant difference of the INTERFACE when controlling traffic for one IAF, $z=-2.23, p<0.05$. The mean time interval was $9 \mathrm{~s}$ shorter for the PVD-TSD interface. The number of IAFs was significant when controlling traffic with the PVD-TSD interface, $z=-3.13, p<0.01$. Adding the second IAF increased the mean time interval with 10 
seconds. A Friedman's ANOVA also indicated a significant effect of the experiment conditions on the time between the initial call and last instruction, $\chi^{2}(3)=48.68, p<0.001$. Again a linear scale response model as described under VII-A was used with the interval between the initial call and last instruction as the response variable. The results of the test of the model effects are summarized in Table 6. All three main effects were significant. Also the interactions between IAF * ENTRY POINT and INTER * ENTRY POINT were significant and were included in the model.

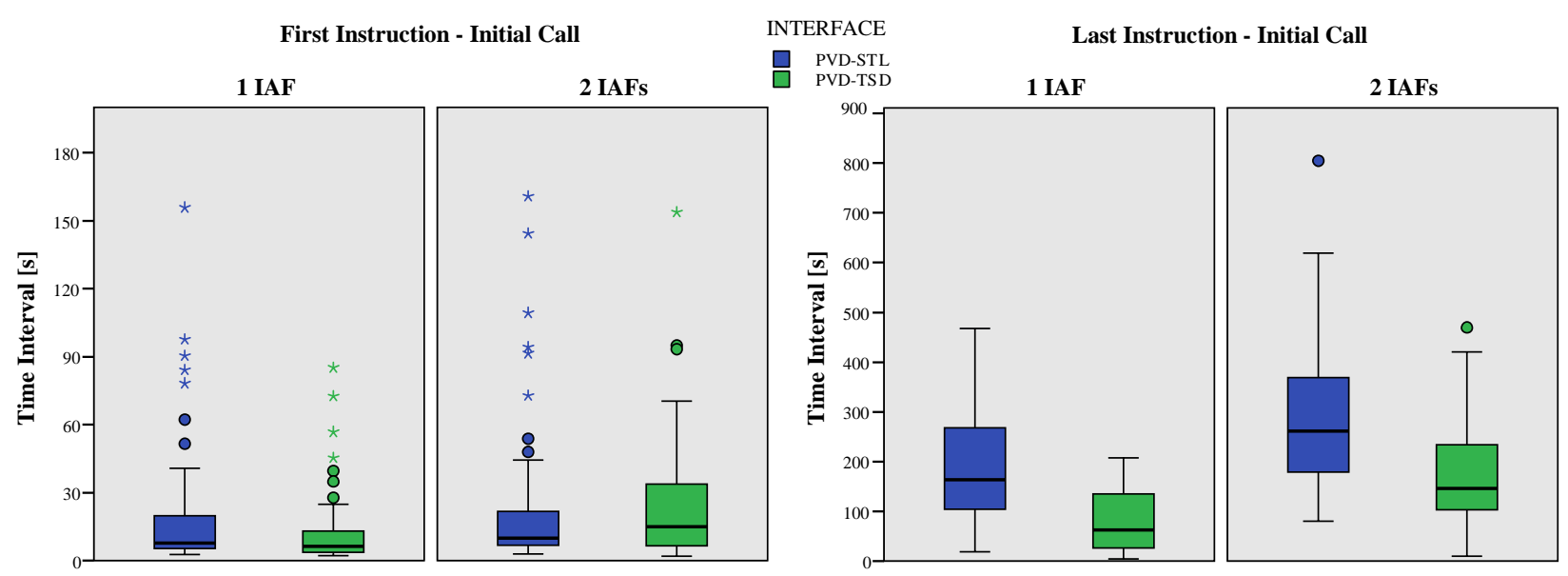

Figure 16. Time intervals between initial aircraft call and the first and last instruction

Table 6. Test of model effects for Time Interval between initial call and last instruction

\begin{tabular}{|l|r|r|r|}
\hline \multirow{2}{*}{ Source } & \multicolumn{3}{|c|}{ Type III } \\
\cline { 2 - 4 } & Wald $\chi^{2}$ & df & \multicolumn{1}{|c|}{ Sig. } \\
\hline IAF & 17.747 & 1 & $<0.001$ \\
ENTRY POINT & 21.516 & 3 & $<0.001$ \\
INTERFACE & 15.390 & 1 & $<0.001$ \\
IAF * INTERFACE & 9.051 & 1 & $<0.01$ \\
IAF * ENTRY POINT & .587 & 1 & .444 \\
INTERFACE * ENTRY POINT & 297.248 & 3 & $<0.001$ \\
IAF * INTERFACE * ENTRY & .028 & 1 & .866 \\
\hline
\end{tabular}

The model parameters and hypothesis tests are given in Table 7. The model explained $39 \%$ of the variance, $r_{s}, p$ $<0.001$. In de model the interval between the initial call and last instruction increased by $87 \mathrm{~s}$ when increasing the number of IAFs. Other significant main effect was the INTERFACE. When controlling traffic using the PVD-TSD interval the interval reduced by $182 \mathrm{~s}$. However, the effect of the interface was smaller when controlling traffic for one IAF. Other significant interaction was the ENTRY POINT LAMSO when controlling traffic using the PVDSTL interface, the interval was $116 \mathrm{~s}$ shorter. 
Table 7. Parameter estimates and hypothesis tests of model for time interval between initial call and last instruction

\begin{tabular}{|c|c|c|c|c|c|c|c|}
\hline \multirow[b]{2}{*}{ Parameter } & \multirow[b]{2}{*}{$\beta$} & \multirow[b]{2}{*}{ Std. Error } & \multicolumn{2}{|c|}{ 95\% Wald Confidence Interval } & \multicolumn{3}{|c|}{ Hypothesis Test } \\
\hline & & & Lower & Upper & Wald $\chi^{2}$ & df & Sig. \\
\hline$[\mathrm{IAF}=1]$ & -87.551 & 37.8250 & -161.687 & -13.416 & 5.358 & 1 & .021 \\
\hline$[\mathrm{IAF}=2]$ & $0^{\mathrm{a}}$ & & & & & & \\
\hline [ENTRY=LAMSO] & -26.008 & 23.8613 & -72.775 & 20.759 & 1.188 & 1 & .276 \\
\hline [ENTRY=REDFA] & 46.570 & 41.1527 & -34.088 & 127.227 & 1.281 & 1 & .258 \\
\hline$[$ ENTRY=DENUT] & -17.074 & 16.3781 & -49.174 & 15.027 & 1.087 & 1 & .297 \\
\hline [ENTRY=HELEN] & $0^{\mathrm{a}}$ & & & & & & \\
\hline$[\mathrm{INT}=\mathrm{PVD}-\mathrm{STL}]$ & 182.091 & 47.5430 & 88.909 & 275.274 & 14.669 & 1 & .000 \\
\hline$[\mathrm{INT}=\mathrm{PVD}-\mathrm{TSD}]$ & $0^{\mathrm{a}}$ & & & & & & \\
\hline$[\mathrm{IAF}=1] *[\mathrm{INT}=\mathrm{PVD}-\mathrm{STL}]$ & -91.279 & 24.3171 & -138.940 & -43.619 & 14.090 & 1 & .000 \\
\hline$[\mathrm{IAF}=1] *[\mathrm{INT}=\mathrm{PVD}-\mathrm{TSD}]$ & $0^{\mathrm{a}}$ & & & & & & \\
\hline$[\mathrm{IAF}=2] *[\mathrm{INT}=\mathrm{PVD}-\mathrm{STL}]$ & $0^{\mathrm{a}}$ & & & & & & \\
\hline$[\mathrm{IAF}=2] *[\mathrm{INT}=\mathrm{PVD}-\mathrm{TSD}]$ & $0^{\mathrm{a}}$ & & & & & & \\
\hline$[\mathrm{INT}=\mathrm{PVD}-\mathrm{STL}] *[\mathrm{ENTRY}=\mathrm{LAMSO}]$ & -116.267 & 10.4720 & -136.792 & -95.742 & 123.269 & 1 & .000 \\
\hline$[\mathrm{INT}=\mathrm{PVD}-\mathrm{STL}] *[\mathrm{ENTRY}=\mathrm{REDFA}]$ & -84.297 & 57.5902 & -197.172 & 28.577 & 2.143 & 1 & .143 \\
\hline$[\mathrm{INT}=\mathrm{PVD}-\mathrm{STL}] *[\mathrm{ENTRY}=\mathrm{DENUT}]$ & 20.071 & 22.4201 & -23.872 & 64.014 & .801 & 1 & .371 \\
\hline$[\mathrm{INT}=\mathrm{PVD}-\mathrm{STL}] *[\mathrm{ENTRY}=\mathrm{HELEN}]$ & $0^{\mathrm{a}}$ & & & & & & \\
\hline$[\mathrm{INT}=\mathrm{PVD}-\mathrm{TSD}] *[\mathrm{ENTRY}=\mathbf{A L L}]$ & $0^{\mathrm{a}}$ & & & & & & \\
\hline
\end{tabular}

a. Set to zero because this parameter is redundant.

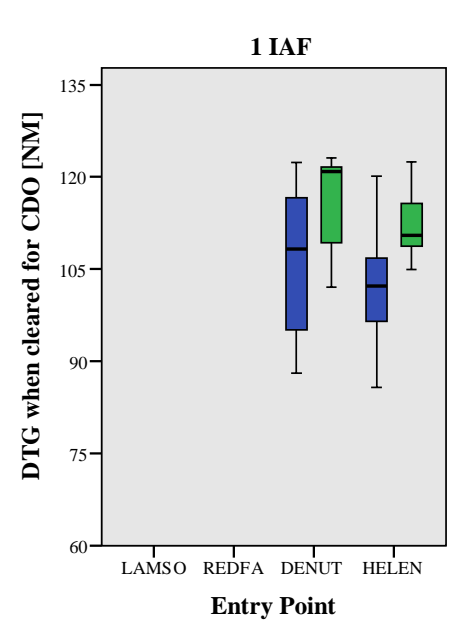

Entry Point

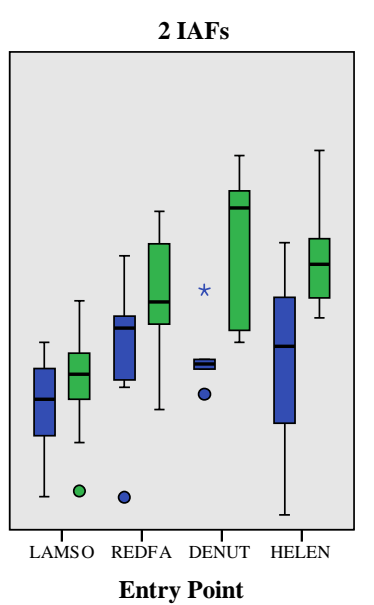

Figure 17. DTG and Altitude when cleared for CDO

\section{CDO Clearance}

Analysis of the timing of the controller instruction prompted a further analysis on the timing of the CDO clearance and effects on the CDO performance. Figure 17 shows the box plot of the DTG when the CDO clearance was received. A linear scale response model was used to investigate the effects of the INTERFACE and IAF. The response variable of the model was the DTG when cleared for CDO. The test of the model effects are summarized in 
Table 8. The main effects INTERFACE, IAF, ENTRY POINT were significant. Also the interactions INTERFACE * IAF and INTERFACE * ENTRY POINT were significant. The parameter estimates and hypothesis tests based on the significant model effects are given in Table 9. The model explained $67 \%$ of the variance, $r_{s}=0.82, p<0.001$. The main significant effect of the ENTRY POINT is clearly the result of the airspace design and not of interest and was therefore removed from the table.

Table 8. Test of model effects for DTG after CDO clearance

\begin{tabular}{|l|r|r|c|}
\hline \multirow{2}{*}{\multicolumn{1}{|c|}{ Source }} & \multicolumn{3}{|c|}{ Type III } \\
\cline { 2 - 4 } & Wald $\chi^{2}$ & df & Sig. \\
\hline INTERFACE & 20.639 & 1 & $<0.001$ \\
IAF & 15.626 & 1 & $<0.001$ \\
ENTRY POINT & 69.050 & 3 & $<0.001$ \\
INTERFACE * IAF & 7.223 & 1 & $<0.01$ \\
INTERFACE * ENTRYPOINT & 128.050 & 3 & $<0.001$ \\
IAF * ENTRY POINT & 1.490 & 1 & .222 \\
INTERFACE * IAF * ENTRY POINT & .058 & 1 & .809 \\
\hline
\end{tabular}

From the model parameters and hypothesis test it was concluded that the main effect INTERFACE had a significant effect. The predicted DTG after the CDO clearance increased with $18 \mathrm{NM}$ when using the PVD-TSD interface instead of the PVD-STL interface. Adding a second IAF also had a negative effect on the DTG. The predicted DTG decreased by $8.9 \mathrm{NM}$. From the interactions it was concluded that the effect of the IAF is not significant when controlling traffic using the PVD-TSD interface but only when controlling traffic using the PVDSTL interface, specifically for traffic arriving from LAMSO (-12 NM). For the other ENTRY points the effects were not significant.

Table 9. Parameter estimates and hypothesis tests of model for DTG after CDO clearance

\begin{tabular}{|c|c|c|c|c|c|c|c|}
\hline \multirow[b]{2}{*}{ Parameter } & \multirow[b]{2}{*}{$\beta$} & \multirow[b]{2}{*}{ Std. Error } & \multicolumn{2}{|c|}{ 95\% Wald Confidence Interval } & \multicolumn{3}{|c|}{ Hypothesis Test } \\
\hline & & & Lower & Upper & Wald $\chi^{2}$ & df & Sig. \\
\hline [INTERFACE $=$ PVD-STL $]$ & -17.711 & 4.0788 & -25.706 & -9.717 & 18.855 & 1 & .000 \\
\hline [INTERFACE $=$ PVD-TSD $]$ & $0^{\mathrm{a}}$ & & & & & r & \\
\hline$[\mathrm{IAF}=1]$ & 8.926 & 3.8957 & 1.291 & 16.561 & 5.250 & 1 & .022 \\
\hline$[\mathrm{IAF}=2]$ & $0^{\mathrm{a}}$ & & & & & & \\
\hline$[$ INTERFACE $=$ PVD-STL $] *[\mathrm{IAF}=1]$ & 7.384 & 2.2852 & 2.905 & 11.863 & 10.442 & 1 & .001 \\
\hline$[$ INTERFACE $=$ PVD-STL $] *[\mathrm{IAF}=2]$ & $0^{\mathrm{a}}$ & & & & & . & \\
\hline$[$ INTERFACE $=$ PVD-TSD $] *[\mathrm{IAF}=1]$ & $0^{\mathrm{a}}$ & & . & & . & . & \\
\hline$[$ INTERFACE $=$ PVD-TSD $] *[\mathrm{IAF}=2]$ & $0^{\mathrm{a}}$ & & & & . & . & \\
\hline$[$ INTERFACE $=$ PVD-STL $] *[$ ENTRY $=$ LAMSO $]$ & 12.402 & 1.6809 & 9.108 & 15.697 & 54.436 & 1 & .000 \\
\hline$[$ INTERFACE $=$ PVD-STL $] *[$ ENTRY $=$ REDFA $]$ & 7.988 & 5.6073 & -3.003 & 18.978 & 2.029 & 1 & .154 \\
\hline$[$ INTERFACE $=$ PVD-STL $] *[$ ENTRY $=$ DENUT $]$ & -.101 & 2.2371 & -4.485 & 4.284 & .002 & 1 & .964 \\
\hline$[$ INTERFACE $=$ PVD-STL $] *[$ ENTRY $=$ HELEN $]$ & $0^{\mathrm{a}}$ & & & & & . & \\
\hline$[$ INTERFACE $=$ PVD-TSD $] *[$ ALL ENTRIES $]$ & $0^{\mathrm{a}}$ & & & & & & \\
\hline
\end{tabular}

a. Set to zero because this parameter is redundant 
The altitude when cleared for the CDO was correlated with the DTG, $r_{s}=0.74, p<0.001$. This indicates that aircraft were cleared for the $\mathrm{CDO}$ at a higher altitude.

\section{F. Aircraft Trajectories}

Analysis of the trajectories focused on the sector time, track miles, and altitude profile.

\section{Sector Time}

Wilcoxon signed rank tests did not indicate a significant effect of the INTERFACE on the time in the ACC sectors for equal number of IAFs under control.

\section{Track Miles}

Figure 18 suggests there was an effect of the INTERFACE and IAF on the miles flown. Figure 19 shows the box plot of the miles flown after the initial call of the aircraft ( 15 NM from entry point). A scale response model was used to further investigate the effects. The response of the model was the track millage. Model predictors were the INTERFACE, IAF, and the ENTRY POINT. To estimate which parameters had to be included in the model a test of the model effects was performed. From the results given in Table 10, it was concluded that INTERFACE and IAF as a main effect were not significant. Only the entry point was significant. The interaction INTERFACE * ENTRY POINT was also significant. It was decided to include the ENTRY POINT and INTERFACE * ENTRYPOINT in the model. Table 11 shows the parameter estimates and hypothesis tests. The model explained $71 \%$ of the variance, $r_{s}=0.85, p<0.001$. The interactions showed that the effect of the PVD-TSD interface on the track miles can be both positive and negative. For entry points HELEN and REDFA, the model predicts an increase of the track millage when controlling track using the PVD-TSD interface. With the PVD-STL interface traffic received directs to the IAF. With the PVD-TSD interface less directs were given. For the points LAMSO and DENUT, the model predicts a decrease of the track millage for the PVD-TSD interface. In the baseline simulation runs, traffic at these entry points was vectored more than with the PVD-TSD interface. The only significant effect is a 1 NM decrease of the track millage for traffic at DENUT. However, the limited sample size shall be taken into account when interpreting these results.
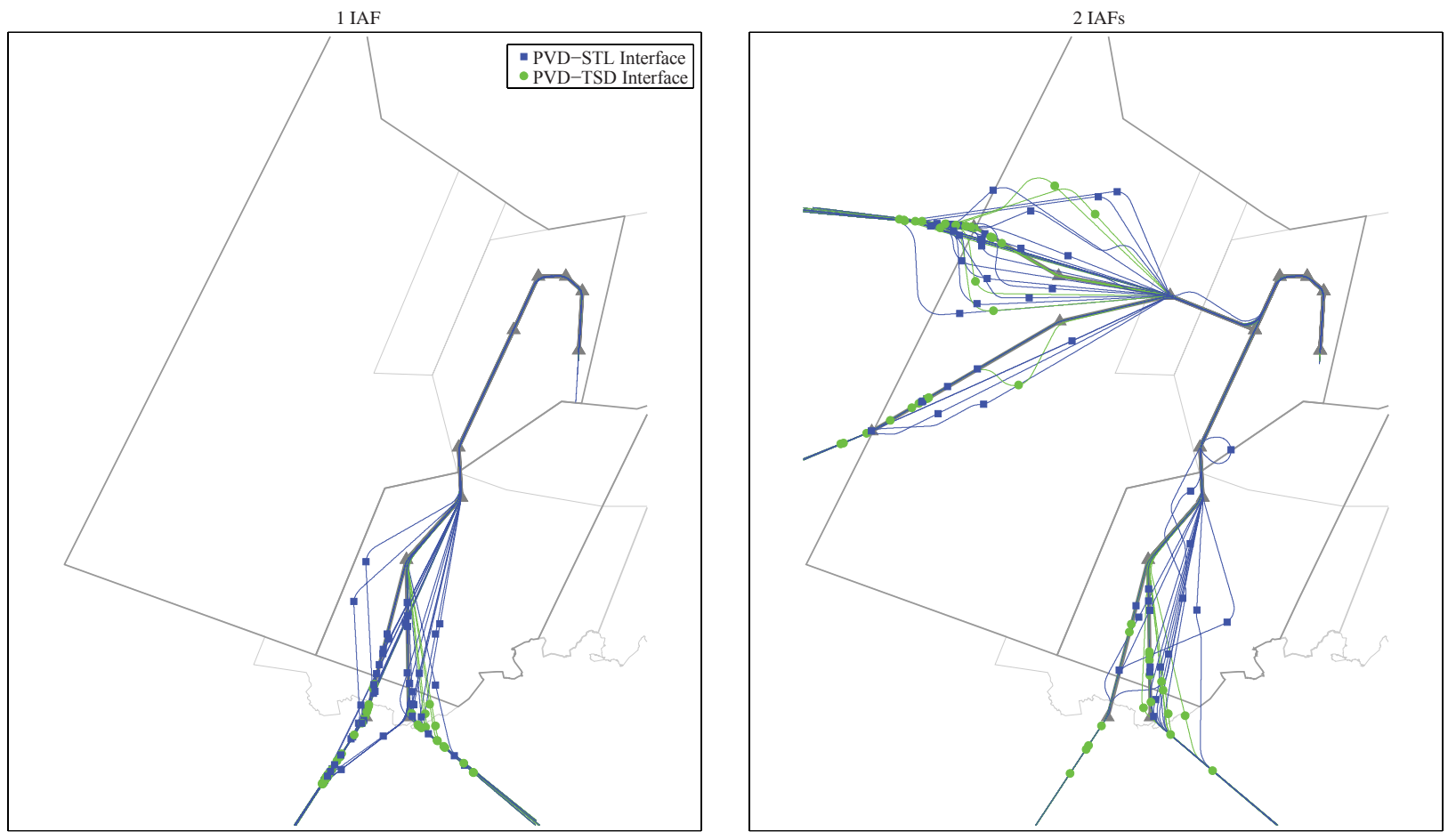

Figure 18. Aircraft trajectories and position when cleared for CDO 
Table 10. Test of model effects for track miles flown

\begin{tabular}{|l|r|c|c|}
\hline \multirow{2}{*}{ Source } & \multicolumn{3}{|c|}{ Type III } \\
\cline { 2 - 4 } & Wald $\chi^{2}$ & df & Sig. \\
\hline INTERFACE & .201 & 1 & .654 \\
IAF & 2.134 & 1 & .144 \\
ENTRY POINT & 2389.660 & 3 & $<0.001$ \\
INTERFACE * ENTRY POINT & 16.608 & 3 & $<0.001$ \\
IAF * ENTRY POINT & .004 & 1 & .951 \\
\hline
\end{tabular}

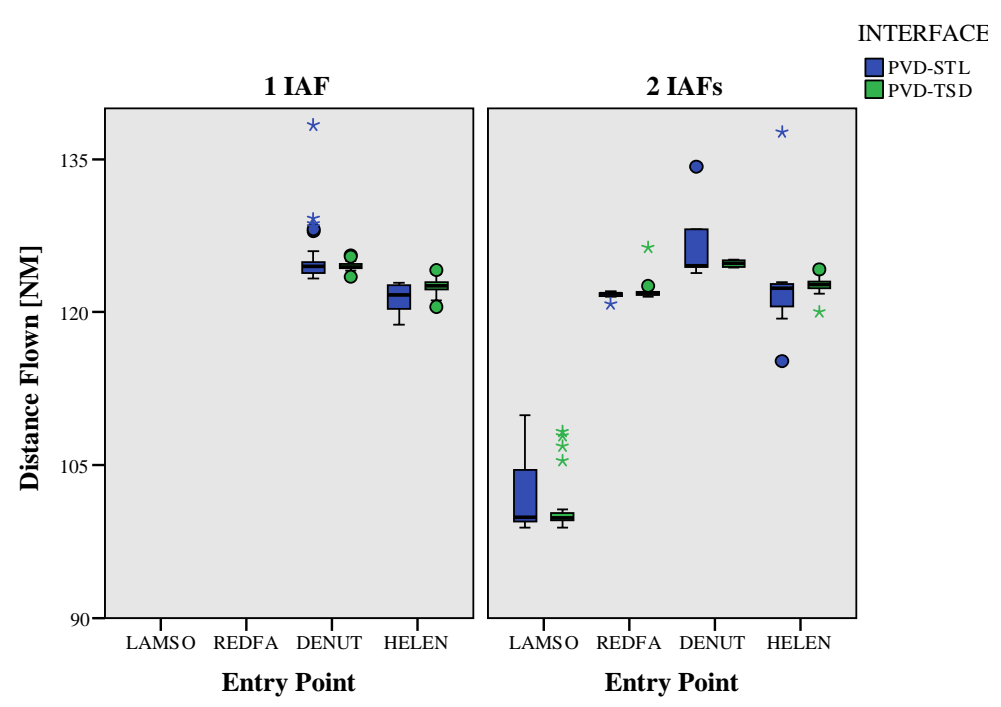

Figure 19. Miles flown after initial aircraft call

Table 11. Parameter estimates and hypothesis tests of track millage model

\begin{tabular}{|c|c|c|c|c|c|c|c|}
\hline \multirow[b]{2}{*}{ Parameter } & \multirow[b]{2}{*}{$\beta$} & \multirow[b]{2}{*}{ Std. Error } & \multicolumn{2}{|c|}{ 95\% Wald Confidence Interval } & \multicolumn{3}{|c|}{ Hypothesis Test } \\
\hline & & & Lower & Upper & Wald $\chi^{2}$ & df & Sig. \\
\hline$[$ INTERFACE $=$ PVD-STL $] *[$ ENTRY $=$ LAMSO $]$ & 1.113 & .9906 & -.829 & 3.054 & 1.262 & 1 & .261 \\
\hline$[$ INTERFACE $=$ PVD-STL $] *[$ ENTRY $=$ REDFA $]$ & -.636 & .4401 & -1.498 & .227 & 2.085 & 1 & .149 \\
\hline$[$ INTERFACE $=$ PVD-STL $] *[$ ENTRY $=$ DENUT $]$ & .991 & .4644 & .081 & 1.901 & 4.555 & 1 & .033 \\
\hline$[$ INTERFACE $=$ PVD-STL $] *[$ ENTRY $=$ HELEN $]$ & -.668 & 6939 & -2.028 & .692 & .927 & 1 & .336 \\
\hline$[$ INTERFACE $=$ PVD-TSD $] *[$ ENTRY $=$ LAMSO $]$ & $0^{\mathrm{a}}$ & . & . & . & . & . & . \\
\hline$[$ INTERFACE $=$ PVD-TSD $] *[$ ENTRY $=$ REDFA $]$ & $0^{\mathrm{a}}$ & . & . & . & . & & . \\
\hline$[$ INTERFACE $=$ PVD-TSD $] *[$ ENTRY $=$ DENUT $]$ & $0^{\mathrm{a}}$ & . & . & . & . & & . \\
\hline$[$ INTERFACE $=$ PVD-TSD $] *[$ ENTRY $=$ HELEN $]$ & $0^{\mathrm{a}}$ & . & . & & & & \\
\hline
\end{tabular}

a. Set to zero because this parameter is redundant. 

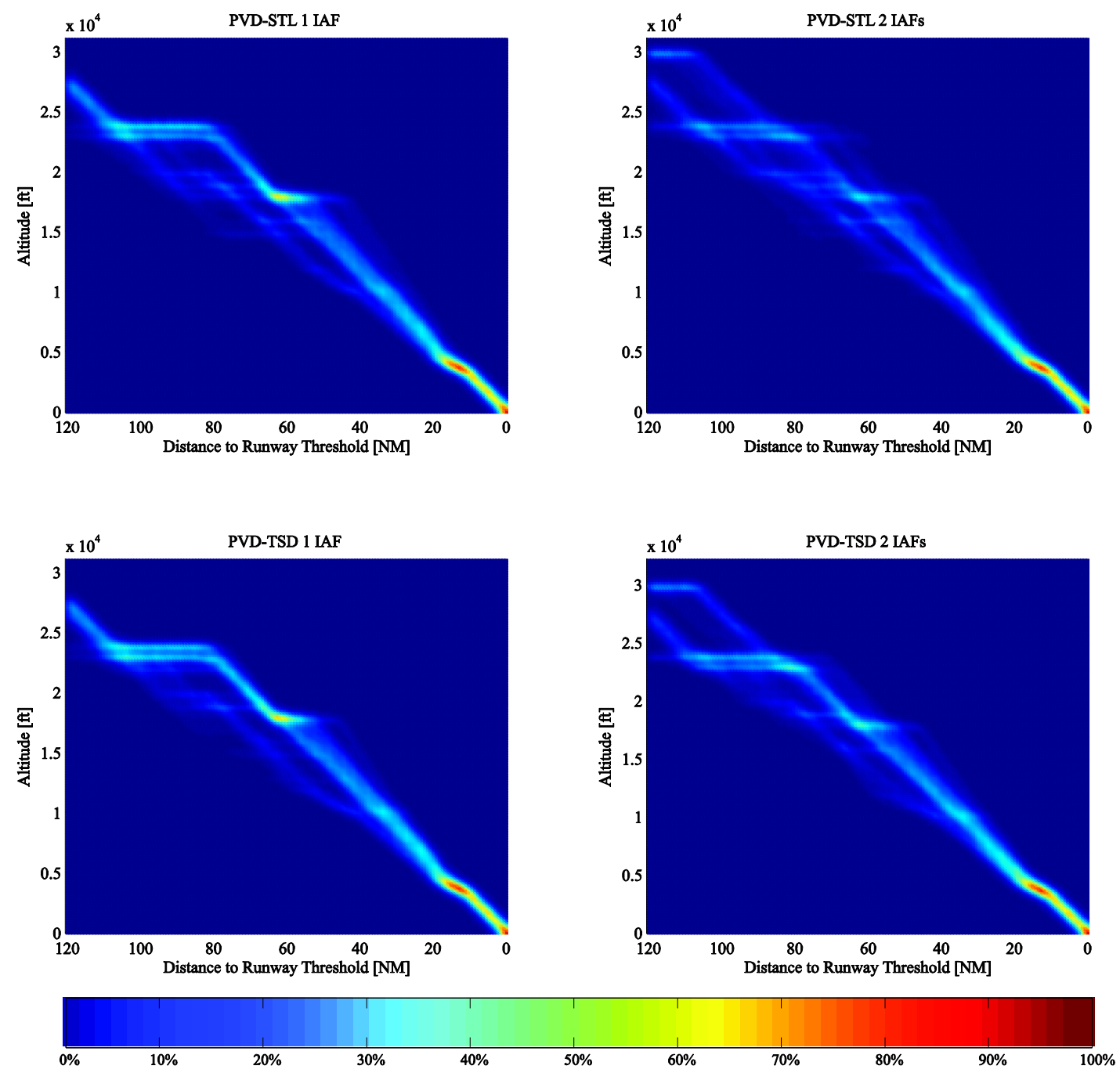

Figure 20. Altitude profiles

\section{Altitude Profile}

Depicted in Figure 20 are density plots of the altitude profiles for each experiment condition. From the plots it was concluded that with the PVD-TSD interface aircraft stay higher for a longer period of time. The effect of the INTERFACE on the altitude where the aircraft were cleared for the CDO is clearly reflected. Also visible is the maximum FL180 at the IAF at approximately $65 \mathrm{NM}$ from the runway. After passing the IAF there were no significant differences between the altitude profiles.

\section{G. Safety}

One loss of separation in the own sector occurred when controlling the aircraft using the PVD-STL interface for two IAFs. The two aircraft involved were both cleared for a CDO. The subject commented that one of the aircraft descended slower than expected and was already monitoring the situation. However, the experiment design did not allow any interventions after CDO clearance.

A Friedman's ANOVA did not indicate any significant effect of the experiment conditions on the final spacing between aircraft, $\chi^{2}(3)=2.09, p 0.55$. The final spacing between aircraft subtracted by the wake separation minimum is plotted in Figure 21. The median of the difference between the final spacing and separation was 0.26 NM for both interfaces. In $20 \%$ of the cases the difference was negative, indicating a potentially unresolved conflict. When observing the experiment, one unresolved conflict for the PVD-STL was counted and two for the PVD-TSD 
interface. The remaining conflicts were identified to be the result of the round off on the PVD-TSD interface, conflicts being masked by the trajectory lines on the PVD-TSD interface, and predictor uncertainty. In these cases the wake vortex separation was not exceeded by more than $0.45 \mathrm{NM}$ with a median of $-0.09 \mathrm{NM}$ and $-.014 \mathrm{NM}$ for the PVD-STL and PVD-TSD interface respectively.

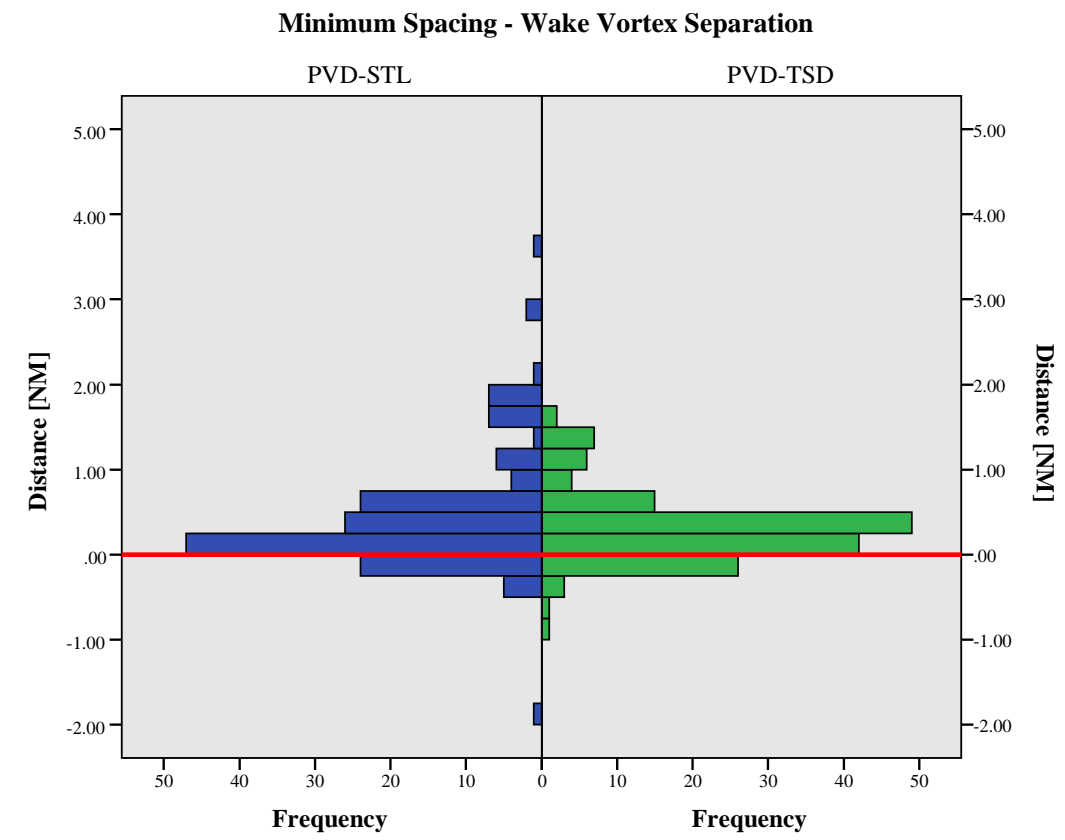

Figure 21. Difference between the minimum spacing and wake vortex separation inside the TMA

\section{H. Throughput}

Table 12 gives the mean and standard deviation of the hourly throughput measured at the runway. The ShapiroWilk test indicated the data of the hourly throughput for the four experiment conditions were not significantly different from a normal distribution $(p>0.05)$. A repeated measure ANOVA did not show any significant main effect of the INTERFACE, IAF on throughput measured at the runway threshold.

Table 12. Mean and standard deviation of the hourly throughput in $\mathrm{AC} / \mathrm{h}$

\begin{tabular}{lcc}
\hline Number of IAFs & PVD-STL & PVD-TSD \\
\hline 1 & $35.3(\sigma=2.32)$ & $35.7(\sigma=0.66)$ \\
2 & $34.2(\sigma=2.32)$ & $34.9(\sigma=0.91)$ \\
\hline
\end{tabular}

\section{Final Questionnaire}

All subjects agreed or strongly with the statement that the TSD provided the necessary information to space traffic for CDO. Four subjects gave the PVD-STL interface the same rating. Two subjects disagreed with the statement. All subjects strongly agreed with the statements that they used the TSD to plan and implement their actions when available. Five subjects strongly agreed with the statement that the information displayed on the PVD and TSD are complementary. One subject strongly agreed with this statement. Two subjects strongly agreed with the statement that the integration of the information displayed on the PVD-TSD interface was easy. Three subjects agreed and one was undecided.

\section{Direct Manipulation Interfaces}

Table 13 summarizes the response to the statement "The following DMI worked intuitively:". None of the DMIs was rate below 'undecided' and these ratings were therefore removed from the table. A Wilcoxon signed-rank test indicated that the DMIs for speed and altitude were rated significantly higher than the waypoint and heading DMIs, $p<0.05$. 
Table 13. Response to the statement "The following DMI worked intuitively:"

\begin{tabular}{lccc}
\hline Parameter & Undecided & Agree & Strongly Agree \\
\hline Speed & 0 & 1 & 5 \\
Altitude & 0 & 1 & 5 \\
Route & 1 & 2 & 3 \\
Direct-To & 1 & 3 & 2 \\
Heading & 1 & 4 & 1 \\
\hline \hline
\end{tabular}

\section{Task Difficulty}

A Wilcoxon signed-rank test was used to analyze the effect of the INTERFACE on the levels of the difficulty to identify conflicts, solutions to conflicts, gaps in the sequence, knock-on effects, and control of aircraft. The modes of the responses are given in Table 14. Confliction identification was rated significantly less difficult for the PVDTSD interface than the PVD-STL interface, $z=-2.27, p<0.05$. Also the difficulty of identifying gaps, $z=-2.06, p<$ 0.05 , knock on effects, $z=-2.27, p<0.05$, and control of the aircraft $z=-2.00, p<0.05$ were rate lower. The effect on identifying a solution to a conflict was not significant, $z=-1.52, p=0.13$.

Table 14. Mode of the level of difficulty of tasks

\begin{tabular}{lcc}
\hline \hline Task & PVD-STL & PVD-TSD \\
\hline Identify conflicts & Easy & Very easy \\
Identify a solution to a conflict & Easy & Very easy \\
Identify knock-on effects & Undecided & Very easy \\
Identify gaps in the sequence & Undecided & Very easy \\
Control the aircraft & Easy & Very easy \\
\hline \hline
\end{tabular}

\section{Control Strategy}

All subjects followed a strategy to first try to resolve a conflict using speed control. Four of the six subjects commented they also used altitude to resolve conflicts, but only for 'fine tuning'. Eventually, heading instructions were used if needed. The reported strategies did not vary with the interface. The subjects did not comment on their strategy to close gaps in the arrival sequence.

\section{Discussion}

The impact of the TSD on the controller interface is significant. Therefore, as an alternative to the TSD, a support tool in the form of a stack list (STL) was developed that would require minimum changes of the interface. The results showed no significant effects of the interface on the capacity and final inter-aircraft spacing. This result was hypothesized, as both interfaces provide the controller with the information to accurately space the aircraft (H1). Significant effects on the controller workload, the overall situational awareness, controller instructions, aircraft trajectories, and CDO performance were found.

According to the ISA and NASA-TLX the workload was lower when using the PVD-TSD interface. The number of IAFs had significant effect on the ISA score only. Adding a second IAF to the scenario lead to an increase of the ISA score (higher workload). The size of this effect, according to the linear response model was half the size of the interface. The NASA-TLX also gave insights in the factors contributing to the experienced workload. The PVDTSD decreased the required effort and mental workload. Absolute judgments of the workload ratings are generally not very meaningful. ${ }^{28}$ From observations and comments made by the subjects it was concluded that workload when using the PVD-TSD interface was very low. The subjects had the time to plan the traffic well ahead and were often waiting on the next aircraft to make its initial call and take control.

The SASHA test allowed for a relative comparison of the level of SA. ${ }^{29}$ The level of SA increased with the PVD-TSD interface and decreased when adding a second IAF independent of the interface. The main effect of the interface on the workload and SA confirmed the hypothesis $H 2$. None of the interactions between the interface and the number of IAFs was significant. The hypothesis $H 3$ that the effect of adding a second IAF would be smaller when using the PVD-TSD interface was not supported.

Further analysis focused on the number of instructions per aircraft and the time interval in which the aircraft received instructions. With the PVD-TSD interface the total number of instructions decreased by $25 \%$. More 
interesting result was the interaction between the interface and the number of IAFs. For the PVD-STL interface the number of instructions increased with the number of IAFs, but for the PVD-TSD interface there was no significant effect. This supported the hypothesis $H 3$ that the effect of the number of IAFs is smaller when using the PVD-TSD interface. Comparing the use of instructions between the interfaces, it was seen that the use of speed control reduced by $50 \%$, from on average two instructions per aircraft to one. The DMIs that were introduced enabled the subjects to accurately set the speed to resolve conflicts or close gaps in the sequence. As a result there was an even bigger effect on the number of instructions that would change the aircraft lateral path. The number of heading instructions and directs decreased by $75 \%$. This was not clearly reflected in the miles flown and the sector time. The route design played a significant role in this. When using the PVD-TSD interface more use of the available STARs was made. However the STARs, did not provide the most direct route between the entry points and IAFs, as can be seen in Figure 10. Aircraft that received instructions to fly a lateral path different from the arrival route possibly flew less track miles to the IAF than aircraft on the STAR, for example for the entry point HELEN as can be seen in Figure 19. Because fewer instructions were given, it was also expected that the instructions were given in a shorter time frame. The analysis showed that the first instruction and last instruction were received earlier when the PVD-TSD interface was used. The last instruction to the aircraft was the clearance for the CDO. When using the PVD-TSD the aircraft received the clearance $18 \mathrm{NM}$ earlier according to the response model. This enabled the aircraft to start the $\mathrm{CDO}$ from greater distance to the runway and from a higher altitude, benefitting the economical and environmental performance as hypothesized in $H 4$.

In previous research ATCos reported difficulties integrating the information displayed on the PVD and TSD and started to focus on the TSD. ${ }^{11,12}$ To resolve these issues the concept of Visual Momentum was applied. In the questionnaire the subjects responded that integrating the information was easy. Also the SASHA questionnaire did not indicate difficulties in building a mental picture of the traffic situation. To analyze whether subjects started to focus on the TSD the selection of aircraft and use of the DMIs was analyzed. Both indicated that the subjects primarily used the PVD to make inputs to the system. These findings were supported by the display used for ISA; $3 \%$ of the total number of ratings was given through the TSD with a maximum of five ratings per simulation run out of 13. One subject commented he had the feeling of being less aware of the greater picture and was focusing primarily on the TSD. This was partly reflected in the SASHA scores. When only one IAF was under control the SASHA score for the PVD-TSD interface was lower. For all other subjects the SASHA scores for the PVD-TSD interface were always higher than the scores for the PVD-STL interface. Additionally, the subject also had the second highest number of inputs on the TSD, but still made most inputs on the PVD. To unambiguously determine focus on either display, information from an eye-tracker is needed.

At the end of the final questionnaire the subjects were asked if they had any suggestions or comments on the two interfaces. The suggestions that were given varied strongly between the subjects and did not indicate clear areas for improvement or a lack of functionality. Various minor changes to the interface were proposed. For the simulator that was used two subjects commented on the text-to-speech technique that was used. The use of single voice did not allow them to identify a flight by the voice.

\section{Conclusion}

The Time-Space Diagram controller support tool (TSD) enables the air traffic controller to accurately space, sequence, and merge traffic for Continuous Decent Operation (CDO) for traffic coming from different directions. Compared to a stack list providing the required spacing and time to loose or gain for CDO, the controller workload was significantly lower at a higher level of situational awareness. Adding a second sector with traffic arriving from a different direction to the scenario had a less significant effect on the traffic handling. The TSD interface freed time to plan traffic ahead using Direct Manipulation Interfaces, which according to all subjects worked intuitively. Early accurate speed control was applied. The number of instructions per aircraft was decreased by $25 \%$ and instructions were given earlier. The number of heading instructions was reduced by $75 \%$. More use was made of the fixed arrival routes. No benefits on the track miles were demonstrated because the arrivals routes did not provide the most direct routing. Because instructions were given earlier aircraft commenced their CDO at a higher altitude and greater distance from the runway.

\section{Acknowledgments}

The authors would like to thank the people that participated in the experiment and EUROCONTROL for granting the use of the Application Programmer's Interface to the Standard Aircraft Modeling Interface and GAME and BADA models. This research is supported in part by the Netherlands Organisation for Scientific Research (NWO) under the Casimir Program. 


\section{References}

${ }^{1}$ EUROCONTROL, "SESAR Master Plan D5: SESAR Definition Phase - Milestone Deliverable 5" DLM-0710-001-02-00, SESAR Consortium for the SESAR Definition Phase Project co-funded by the European Commission and EUROCONTROL, April 2008.

${ }^{2}$ Joint Planning and Development Office (JPDO), "NextGen Integrated Work Plan: A Functional Outline,” Tech. rep., Joint Planning and Development Office, 2008.

${ }^{3}$ ICAO, "Environmental Report 2010, Aviation and Climate Change", 2010.

${ }^{4}$ Ren, L., and Clarke, J.-P. B., "A Separation Analysis Methodology for Designing Area Navigation Arrival Procedures," Journal of Guidance, Control, and Dynamics, Vol. 30, No. 5, 2007, pp. 1319-1330.

${ }^{5}$ Ren, L., and Clarke, J.-P. B., "Flight-Test Evaluation of the Tool for Analysis of Separation and Throughput," Journal of Aircraft, Vol. 45, No. 1, 2008 pp. 323-332.

${ }^{6}$ Reynolds, H. J. D., Reynolds, T. G., and Hansman, R. J., "Human Factors Implications of Continuous Descent Approach Procedures for Noise Abatement in Air Traffic Control," 6rd USA/Europe Air Traffic Management R\&D Seminar, Baltimore, WA, USA, 2005.

${ }^{7}$ Erkelens, L. J. J., "Research into New Noise Abatement Procedures for the 21st Century,” AIAA Paper 2000-4474, Aug. 2000 .

${ }^{8}$ de Jong, T. G., A Review on Air Traffic Management, Unpublished Preliminary MSc. Thesis, Faculty of Aerospace Engineering, Delft University of Technology, Delft, The Netherlands, 2006.

${ }^{9}$ Tielrooij, M., In 't Veld, A. C., Mulder, M., and Van Paassen, M. M., "Assisting ATC in Metering, Sequencing and Merging Arrival Streams in Three-Degree Decelerating Approaches," Proceedings of the 27th European Annual Conference on Human Decision Making and Manual Control, Delft, The Netherlands, June 12-13, 2008.

${ }^{10}$ Tielrooij, M., In 't Veld, A. C., Mulder, M., and Van Paassen, M. M., "Development of a Time-Space Diagram to Assist Air Traffic Controllers in Monitoring Continuous Descent Approaches," Air Traffic Control, edited by M. Mulder, Sciyo, Rijeka, Croatia, August 2010, pp. 135- 147.

${ }^{11}$ van der Eijk, A., M. Mulder, M.M. van Paassen, and In't Veld, A.C. "Assisting Air Traffic Control in Planning and Monitoring Continuous Descent Approach Procedures," AIAA Guidance, Navigation and Control Conference \& Exhibit, Chicago (IL), August 15-18, , No. AIAA 2009-6163, 2009.

${ }^{12}$ van Dijk, E., Mulder, M., Van Paassen, M. M., and Roerdink, M. I., “An Interface for Inbound Traffic Management by Air Traffic Control," Proceedings of the AIAA Guidance, Navigation and Control Conference, Chicago (IL), USA, August 10-13, , No. AIAA 2009-6164, 2009.

${ }^{13}$ ICAO, "Continuous Descent Operation (CDO) Manual," Doc. 9931 AN/479, advanced edition, 2010.

${ }^{14}$ Kershaw, A. D., Rhodes, D. P., and Smith, N. A., "The influence of ATC in approach noise abatement," 3rd USA/Europe Air Traffic Management R\&D Seminar Napoli , 2000.

${ }^{15}$ Garber, N.J., Hoel, L.A., Traffic \& Highway Engineering, University of Virginia, Cengage Learning Engineering, 2010.

${ }^{16}$ United States Department of Transport, Traffic Signal Timing Manual, Kittelson \& Associates. Inc., Cengage Learning Engineering, June 2008.

${ }^{17}$ Young, S. B., Wells, A.T, Airport Planning \& Management, McGraw-Hill Companies, Inc., $6^{\text {th }}$ ed., 2011., pp. 436.

${ }^{18}$ Vicente, K. J. and Rasmussen, J., "Ecological Interface Design: Theoretical Foundations," IEEE Transactions on Systems, Man, and Cybernetics, Vol. 22, No. 4, July/August 1992, pp. 589-606.

${ }^{19}$ Peters, M., and Konyak, M. A., "The Engineering Analysis and Design of the Aircraft Dynamics Model for the FAA Target Generation Facility," Seagull Technology, Inc., Los Gatos, CA, November 2003

${ }^{20}$ Ren, L., Ho, N. T., and Clarke, J.-P. B., "Workstation Based Fast-Time Aircraft Simulator for Noise Abatement Approach Procedure Study,” AIAA Paper 2004-6503, September 2004.

${ }^{21}$ Anon., "Standard Aircraft Modeling Interface," Users guide (draft) rev. 4.2, EUROCONTROL Headquarters, Brussels, Belgium, April 2009.

${ }^{22}$ Anon., "G.A.M.E. Aircraft Performance Model,” Report ver. 2.0, EUROCONTROL Headquarters, Brussels, Belgium, September 2002.

${ }^{23}$ Anon., "User Manual for the Base of Aircraft Data (BADA), Revision 3.6," EUROCONTROL Experimental Center, Brussels, Belgium, September 2004.

${ }^{24}$ Woods, D. D., "Visual Momentum: A concept to improve the cognitive coupling of person and computer," International Journal of Man-Machine Studies, Vol. 21, No. 3, September 1984, pp. 229-244.

${ }^{25}$ Kaber, D.B., Riley, J.M., Tan, K., Endsley, M.R., "On the design of adaptive automation for complex systems.," International Journal of Cognitive Ergonomics, Vol. 5, 2001, pp. 37-57.

${ }^{27}$ Hutchins, E. L., Hollan, J. D., and Norman, D. A., "Direct Manipulation Interfaces,” Human-Computer Interaction, Vol. 1, 1985, pp. 311-338.

${ }^{28}$ Hart, S. G. and Staveland, L. E., "Development of NASA-TLX (Task Load Index): Results of empirical and theoretical research," Human Mental Workload, edited by P. A. Hancock and N. Meshkati, Elsevier Science Publishers, Amsterdam, The Netherlands, 1988, pp. 139-183.

${ }^{29}$ Straeter, O., Woldring, V. S. M., Barbarino, M., Skoniezki, A., and Philipp, W., "The Development of Situation Awareness Measures in ATM Systems," Tech. Rep. HRS/HSP-005-REP-01; 1.0, EUROCONTROL Headquarters, Brussels, Belgium, June 2003. 
${ }^{30}$ Liao, T. F., Interpreting Probability Models: Logit, Probit, and Other Generalized Linear Models, chap. 5, Sage Publications, 1994, pp. 41-43.

American Institute of Aeronautics and Astronautics 